\title{
Mutation of a barrier insulator in the human ankyrin-1 gene is associated with hereditary spherocytosis
}

\author{
Patrick G. Gallagher, ${ }^{1,2}$ Laurie A. Steiner, ${ }^{1}$ Robert I. Liem, ${ }^{3}$ Ashley N. Owen, ${ }^{3}$ \\ Amanda P. Cline, ${ }^{3}$ Nancy E. Seidel, ${ }^{3}$ Lisa J. Garrett, ${ }^{3}$ and David M. Bodine ${ }^{3}$ \\ ${ }^{1}$ Departments of Pediatrics and ${ }^{2}$ Genetics, Yale University School of Medicine, New Haven, Connecticut, USA. \\ ${ }^{3}$ Hematopoiesis Section, Genetics and Molecular Biology Branch, National Human Genome Research Institute, NIH, Bethesda, Maryland, USA.
}

\begin{abstract}
Defects of the ankyrin-1 gene are the most common cause in humans of hereditary spherocytosis, an inherited anemia that affects patients of all ethnic groups. In some kindreds, linked $-108 /-153$ nucleotide substitutions have been found in the upstream region of the ankyrin gene promoter that is active in erythroid cells. In vivo, the ankyrin erythroid promoter and its upstream region direct position-independent, uniform expression, a property of barrier insulators. Using human erythroid cell lines and primary cells and transgenic mice, here we have demonstrated that a region upstream of the erythroid promoter is a barrier insulator in vivo in erythroid cells. The region exhibited both functional and structural characteristics of a barrier, including prevention of gene silencing in an in vivo functional assay, appropriate chromatin configuration, and occupancy by barrier-associated proteins. Fragments with the $-108 /-153$ spherocytosis-associated mutations failed to function as barrier insulators in vivo and demonstrated perturbations in barrier-associated chromatin configuration. In transgenic mice, flanking a mutant -108/-153 ankyrin gene promoter with the well-characterized chicken HS4 barrier insulator restored position-independent, uniform expression at levels comparable to wild-type. These data indicate that an upstream region of the ankyrin-1 erythroid promoter acts as a barrier insulator and identify disruption of the barrier element as a potential pathogenetic mechanism of human disease.
\end{abstract}

\section{Introduction}

The hereditary spherocytosis syndromes are a heterogeneous group of disorders characterized by anemia, intermittent jaundice, splenomegaly, and sphere-shaped (spherocytic) erythrocytes on peripheral blood smear (1). Hereditary spherocytosis affects patients in all ethnic groups worldwide and is the most common cause of inherited anemia in people of Northern European ancestry. The primary biochemical defects in spherocytosis erythrocytes are qualitative or quantitative abnormalities of proteins of the erythrocyte membrane. Mutations in the gene encoding the membrane protein ankyrin-1 (ANK1; OMIM 182900), primarily frameshift or nonsense mutations, are the most common cause of hereditary spherocytosis (2-4).

Sequence variations have been identified in the region upstream of ankyrin erythroid exon 1 (1E) in the erythroid promoter region in patients with both dominant and recessively inherited ankyrindeficient hereditary spherocytosis $(1,5)$. Two linked variants, $-108 \mathrm{~T} \rightarrow \mathrm{C}$ and $-153 \mathrm{G} \rightarrow \mathrm{A}$, were discovered in several kindreds with ankyrin-deficient spherocytosis who lacked other causative mutations (5-7). Neither variant is located in known critical regions of promoter function, e.g., transcription initiation sites or transcription factor-binding sites (8). Transgenic mice with a wild-type ankyrin gene erythroid promoter linked to a ${ }^{A} \gamma$-globin reporter gene exhibit erythroid-specific, position-independent, uniform expression of the $\mathrm{A} \gamma$-globin reporter gene (9). In contrast, mice carrying a mutant $-108 /-153$ ankyrin gene promoter exhibit significantly lower levels of ${ }^{A} \gamma$-globin mRNA, loss of position-independent expression, and loss of uniform $\gamma$-globin protein expres-

Conflict of interest: The authors have declared that no conflict of interest exists. Citation for this article: J Clin Invest. 2010;120(12):4453-4465. doi:10.1172/JCI42240. sion in erythrocytes (10). These data indicated that the $-108 /-153$ allele is associated with perturbations in ankyrin expression, but did not reveal the mechanism of these abnormalities.

Insulators are DNA sequences and their associated binding proteins that establish and/or maintain boundaries between regions of active and silenced chromatin domains $(11,12)$. They often flank gene clusters or loci, or are tightly associated with gene promoters (13), but do not themselves cause an increase in the rate of transcription (11). One type of insulator, known as an enhancerblocking insulator, establishes chromatin domains to separate enhancers and promoters, preventing their interaction $(12,14)$. A second type of insulator, known as a barrier insulator, creates a barrier to protect against heterochromatin-mediated gene silencing. Defined by their functional characteristics, barrier insulators are thought to function by preventing the spread of heterochromatic proteins into adjoining euchromatin domains (15-18). Despite their role as critical regulators of tissue-specific gene expression, mechanisms controlling barrier insulator structure and function in mammalian cells are poorly understood $(19,20)$. Only a few barriers have been described in vertebrates $(16,21-23)$, with most of our knowledge coming from detailed studies of the well-characterized chicken $\beta$-globin 5'HS4 (cHS4) barrier insulator (24-27).

Based on the remarkable position-independent (25 of 25), uniform expression conferred by the minimal wild-type ankyrin gene erythroid promoter in transgenic mouse lines $(9,10)$, we hypothesized that a region of the ankyrin erythroid promoter functions as a barrier insulator and that the $-108 /-153$ mutations alter this barrier activity, leading to a reduction in ankyrin expression. In this report, we show that the -282 to -101 region upstream of the ankyrin gene erythroid promoter is a barrier insulator in erythroid cells, exhibiting both functional and structural characteristics of a 
A
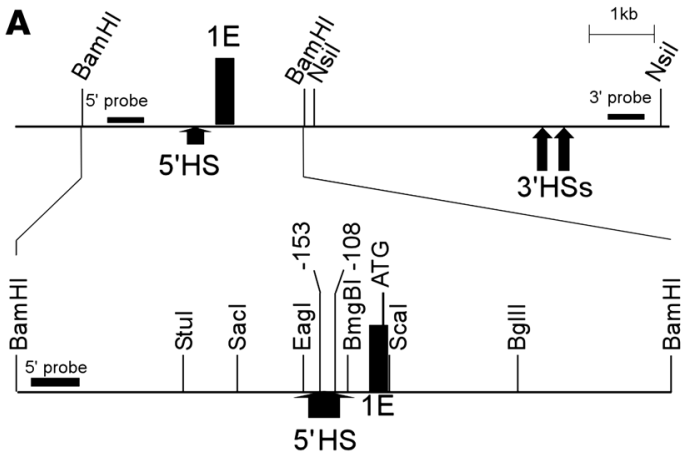

B

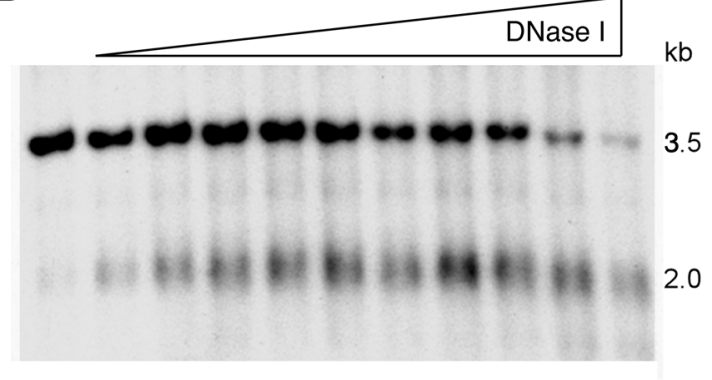

D

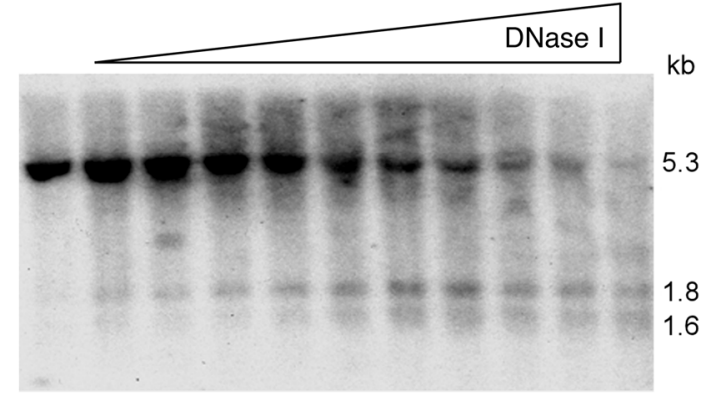

\section{Figure 1}

C

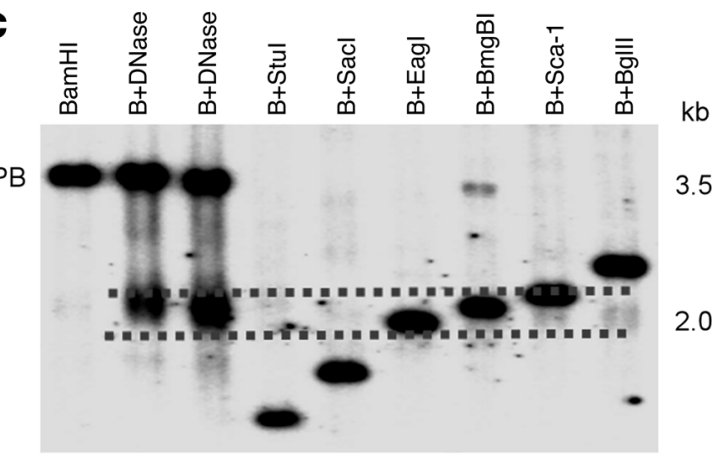

$\mathrm{kb}$

3.5

2.0

Mapping DNase I HSs in the erythroid promoter region of the ankyrin-1 locus in erythroid cells. (A) The map indicates the position of ankyrin exon $1 \mathrm{E}$, flanking restriction enzyme sites, and probes used in DNase I mapping. A close-up view of the BamHI fragment with appropriate restriction enzyme sites, the -108 and -153 mutations, and exon 1E is also shown. Corresponding coordinates are (GRCh37/hg19) BamHI 41657070; Stul 41656031; Sacl 41655737; Eagl 41655310; 153 mutation 41655209; -108 mutation 41655164; BmgBI 41655152; ATG. (B) Mapping 5' of exon $1 \mathrm{E}$. Nuclei from K562 cells were treated with increasing amounts of DNase I, digested with BamHI, and subjected to Southern blot analysis using the $5^{\prime}$ probe in A. This yielded the expected 3.5-kb BamHI fragment and a smaller, 2.0-kb fragment corresponding to a DNase I HS. (C) Fine mapping the $5^{\prime}$ HS. Human genomic DNA digested with BamHI (B) or with BamHI and the indicated second enzyme. DNA from DNase I-treated K562 nuclei was also digested with BamHI (B+DNase). These digests were subjected to Southern blot analysis using the $5^{\prime}$ probe in A. Dashed lines indicate the estimated upper and lower limits of $5^{\prime} \mathrm{HS}$. The undigested parent band is indicated (PB). (D) Mapping $3^{\prime}$ of exon $1 \mathrm{E}$. Nuclei from K562 cells were treated with increasing amounts of DNase I, digested with Nsil, and subjected to Southern blot analysis using the $3^{\prime}$ probe in A. This yielded the expected 5.3-kb Nsil fragment and two smaller, 1.8-kb and 1.6-kb fragments, corresponding to DNase I HSs.

barrier, including prevention of gene silencing in an in vivo functional assay, appropriate chromatin configuration, and occupancy of barrier-associated proteins. Upstream promoter fragments with the $-108 /-153$ spherocytosis-associated mutations, which are contained in this upstream region, fail to function as a barrier insulator in vivo and demonstrate perturbations in barrier-associated chromatin configuration and binding of barrier-associated proteins. In transgenic mice, flanking the mutant $-108 /-153$ ankyrin erythroid promoter transgene with the cHS4 barrier insulator completely restored position-independent, uniform expression at levels comparable to wild-type. These studies are the first to our knowledge to identify disruption of a barrier insulator as a pathogenetic mechanism of human disease.

\section{Results}

Identification of a DNase I bypersensitive site in the region upstream of the ankyrin erythroid promoter. Insulators with barrier activity frequently are associated with DNase I hypersensitive sites (HSs) (20). DNase I HS mapping in the ankyrin erythroid promoter region identified a DNase I HS immediately $5^{\prime}$ to the promoter in chromatin from erythroid (K562) cells (Figure 1). Fine HS mapping revealed that this HS includes $181 \mathrm{bp} 5^{\prime}$ of the promoter region between -282 to -101 (designated 5'HS; UCSC hg19 coordinates chr8:41656031 to 41655152; Figure 1), which includes sequences previously shown to be necessary and sufficient for uniform, copy number-dependent, position-independent expression of a linked reporter gene in transgenic mice ( -296 to -15$)$ and contains the spherocytosis-associated -108 and -153 promoter mutations. We hypothesized the $5^{\prime} \mathrm{HS}$ region defines the location of a barrier insulator in erythroid cells.

DNase I HSs flanking the ankyrin erythroid promoter region define an erythroid chromatin domain. Barrier insulators frequently identify tissue-specific chromatin domains $(12,13)$, and these domains are delineated by DNase I HSs flanking nucleosome-free regions (20). To ascertain whether the 5'HS region containing the $-108 /-153$ mutations identified an erythroid chromatin domain flanked by DNase I HSs, we performed a series of DNase I-based experiments. DNase I HS mapping was performed 3' of the ankyrin erythroid promoter region. This mapping identified two closely spaced HS sites approximately $5.0 \mathrm{~kb}$ downstream of exon $1 \mathrm{E} / 5^{\prime} \mathrm{HS}$ in chromatin from erythroid (K562) cells ( $3^{\prime} \mathrm{HS} 1$ and $3^{\prime} \mathrm{HS} 2$; Figure 1 ). In cHS4 and barriers from model organisms, barrier-associated HSs are present in all cells regardless of whether the locus is expressed. 


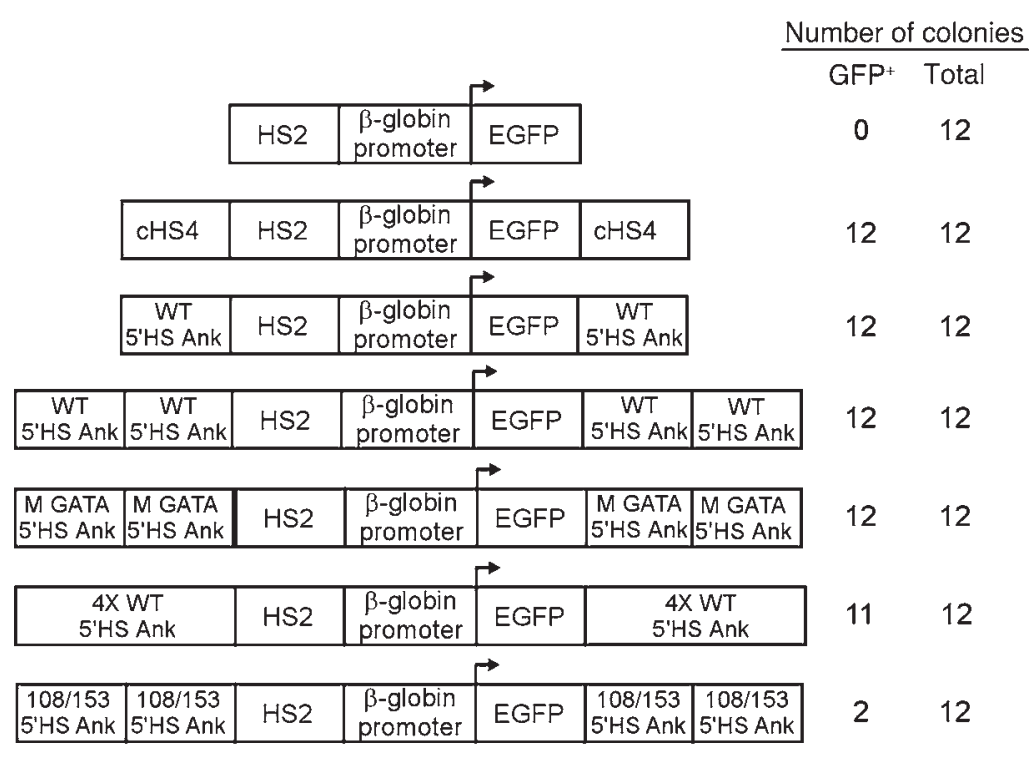

Consistent with these observations, both $5^{\prime} \mathrm{HS}$ and $3^{\prime} \mathrm{HS} 1 / 3^{\prime} \mathrm{HS} 2$ were present in K562 and chromatin from neural (SH SY5Y), embryonic kidney (293T), T cell (Jurkat and primary human CD4 ${ }^{+}$ lymphocytes), and epithelial-like (HeLa) cells (data not shown and Supplemental Figure 1; supplemental material available online with this article; doi:10.1172/JCI42240DS1). Our recent work demonstrates that K562 cells are a good model for the study of ankyrin-1 gene regulation in erythroid cells (28). Compared with

\section{Figure 2}

Analysis of barrier insulator function in a position-effect variegation/gene silencing assay. The indicated constructs were cotransfected into K562 cells with a pRSVneo selection plasmid. Individual clones were isolated and expanded in G418-containing medium and switched to nonselective medium before analysis of GFP expression by FACS. GFP expression was reassessed at 3, 12, and 16 weeks. The number of GFP-expressing (GFP+) clones at 16 weeks and the total number of clones analyzed are shown. HS2, HS2 from the $\beta$-globin gene locus control region; EGFP, the coding sequence for the enhanced GFP gene; cHS4, HS4 from the chicken $\beta$-globin cluster; WT $5^{\prime} \mathrm{HS}$ Ank, a fragment containing the ankyrin $5^{\prime} \mathrm{HS}$ region; M GATA, the ankyrin $5^{\prime} \mathrm{HS}$ region with a mutation of the GATA1 site that abolished ankyrin promoter activity in vitro; 4X WT 5' HS Ank, 4 copies of the ankyrin $5^{\prime} \mathrm{HS}$ region; 108/153 5'HS Ank, the ankyrin $5^{\prime} \mathrm{HS}$ region with the -108 and -153 mutations.

primary human erythroid cells, K562 cells express similar levels of ankyrin mRNA, the chromatin architecture is similar, and binding of the transcription factors GATA-1 and NF-E2 is identical.

Actively transcribed regions of chromatin are sensitive to DNase I digestion, while inactive regions of chromatin are DNase I resistant. To determine whether $5^{\prime} \mathrm{HS}$ and $3^{\prime} \mathrm{HS} 1 / 3^{\prime} \mathrm{HS} 2$ defined an erythroid-specific chromatin domain, nuclei from various cell types was digested with DNase I and analyzed for DNase I sensitivity

Figure 3

Analysis of enhancer-blocking function. The constructs shown were transfected into K562 cells, followed by plating of cells in semisolid medium to allow growth of individual clones. Individual clones were counted after 14 days. The relative number of colonies was normalized at 100 to either HS2 $\gamma$-globin promoter Neo (A) or G1E $\gamma$-globin promoter Neo (B), shown by the graphs on the right. HS2, HS2 from the $\beta$-globin locus control region; $\mathrm{Neo}^{\mathrm{R}}$, the coding sequence for the neomycin resistance gene; cHS4, HS4 from the chicken $\beta$-globin cluster; WT 5'HS Ank, a fragment containing the ankyrin $5^{\prime} \mathrm{HS}$ region; 108/153 5'HS Ank, the ankyrin 5 'HS ankyrin region with the -108 and -153 mutations; G1E, an enhancer element from the mouse GATA-1 locus.

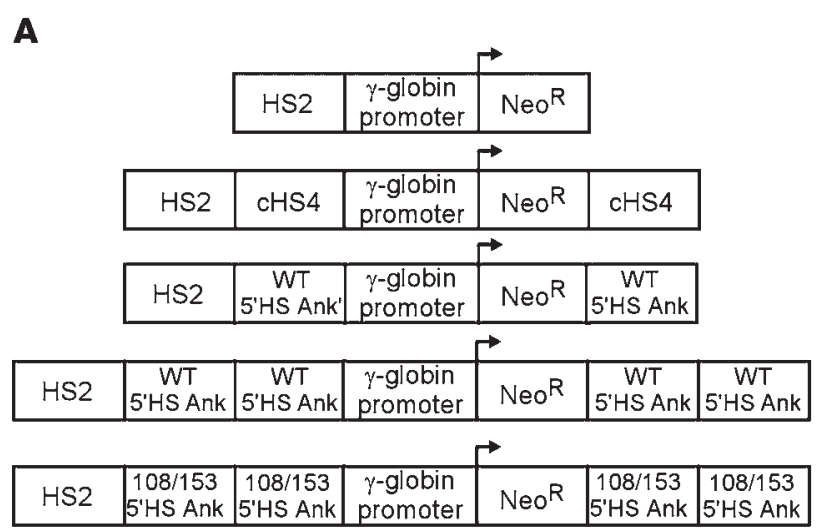

B

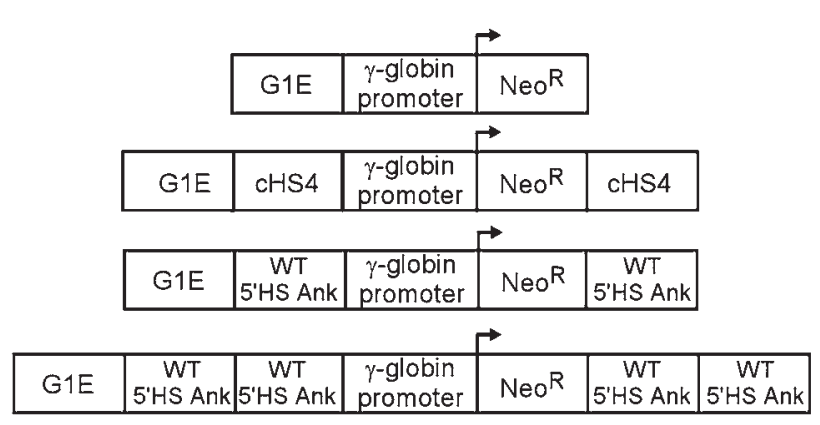

G418R colonies

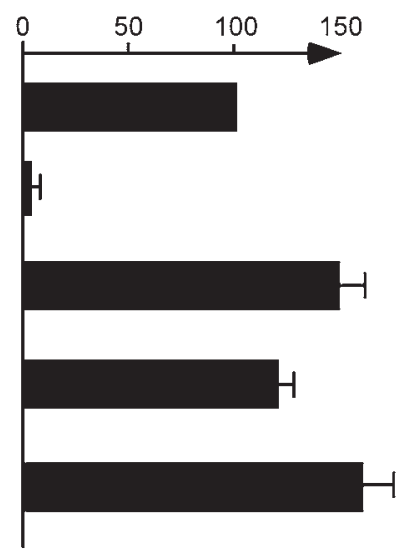

G418R colonies

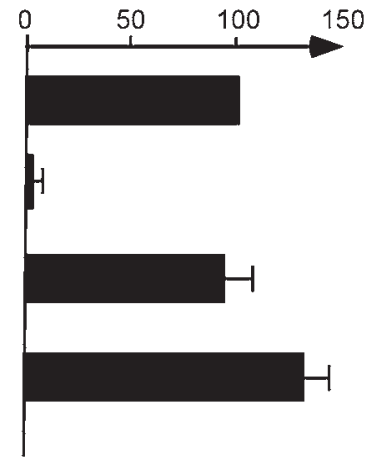



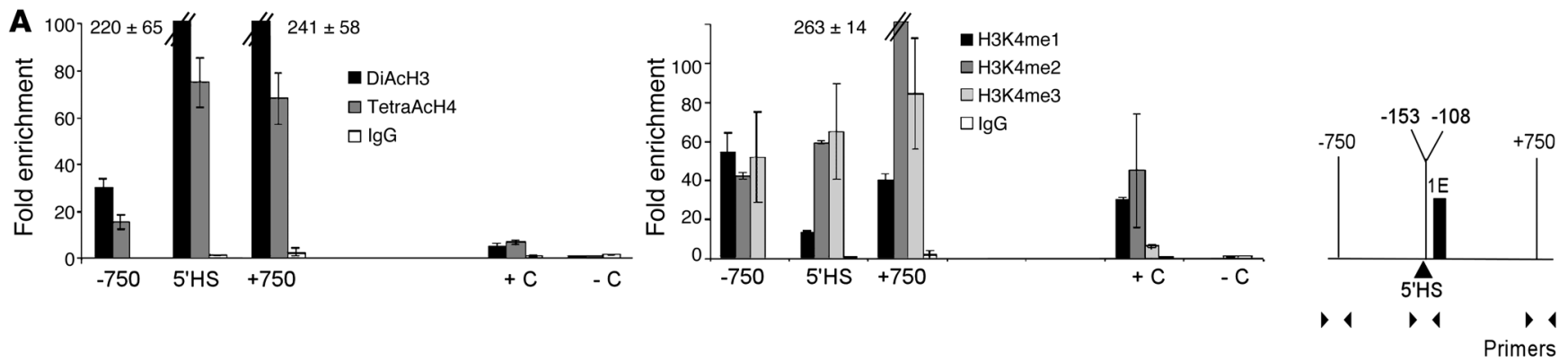

B
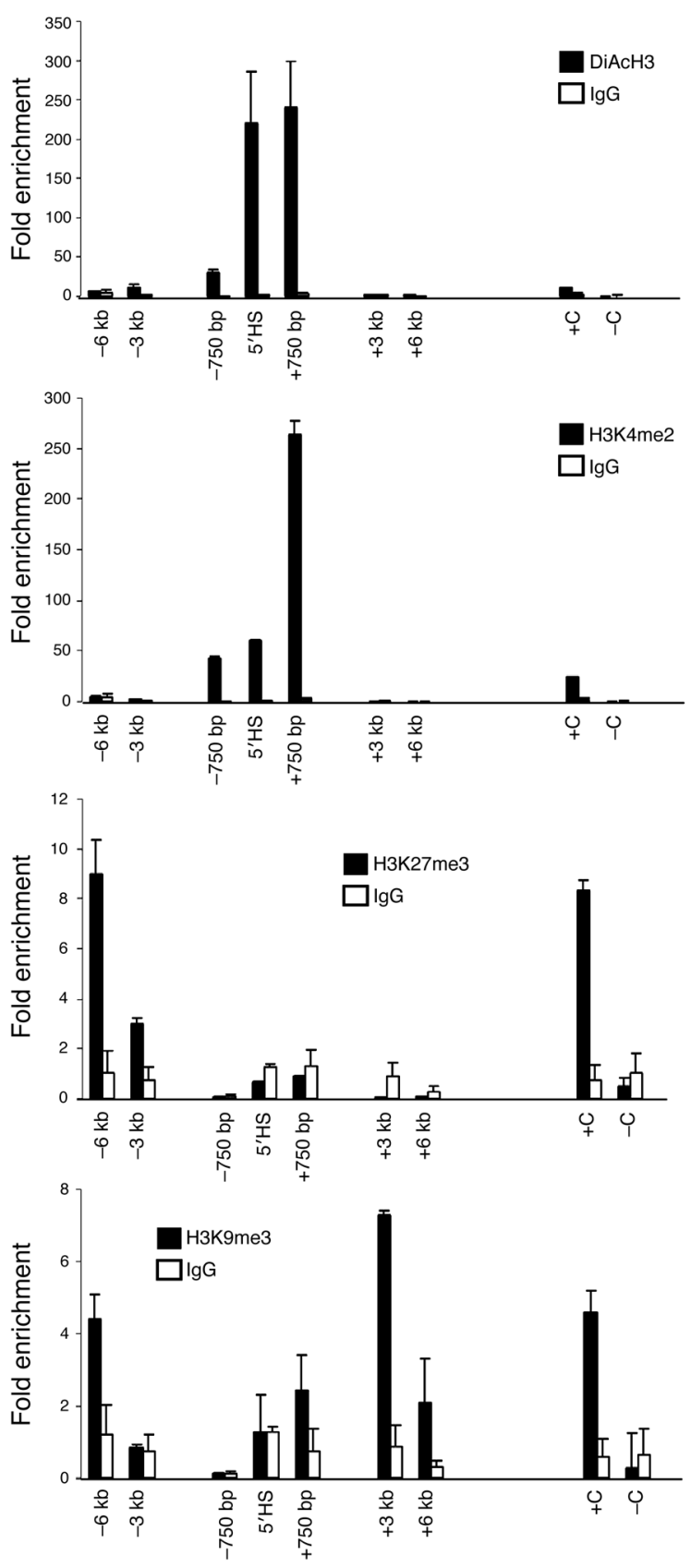

Primary erythroid cells
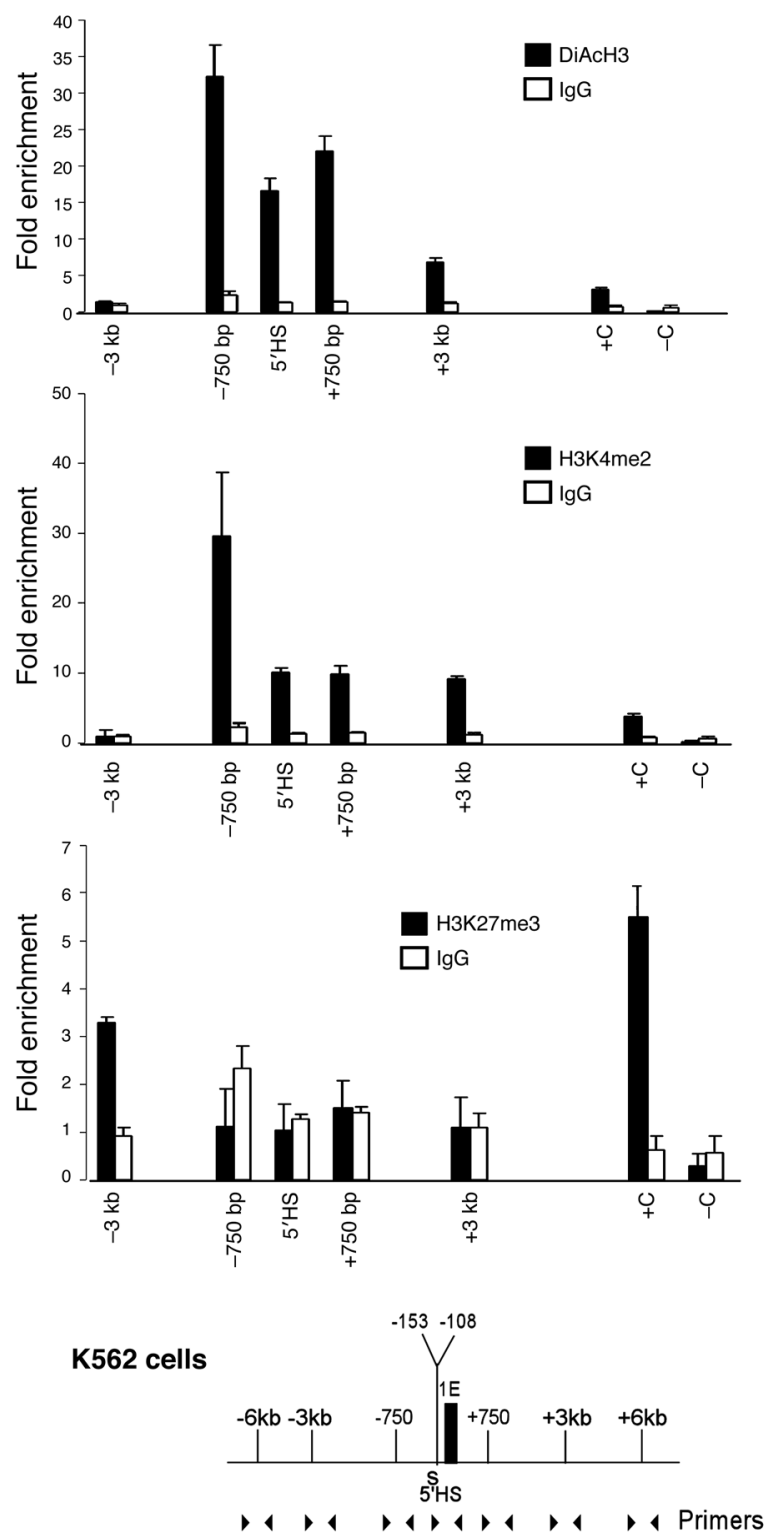

Primary erythroid cells

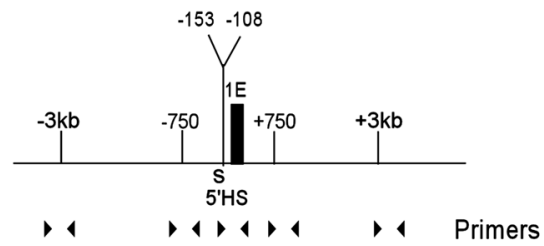




\section{Figure 4}

Quantitative ChIP analyses of chromatin architecture in the ankyrin-1 $5^{\prime} \mathrm{HS}$ region. ChIP studies examining posttranslational histone modifications around the 5'HS region. (A) Left panel: ChIP with antibodies against diacetylated histone $\mathrm{H} 3(\mathrm{DiAcH} 3)$ and tetraacetylated histone H4 (TetraAcH4) and K562 chromatin. Middle panel: ChIP with antibodies against $\mathrm{H} 3 \mathrm{~K} 4 \mathrm{me} 1, \mathrm{H} 3 \mathrm{~K} 4 \mathrm{me} 2$, and $\mathrm{H} 3 \mathrm{~K} 4 \mathrm{me}$. HS2 of the $\beta$-globin locus (93) was included as a positive control $(+C)$, and a region of hsSat2 (94) was included as a negative control $(-\mathrm{C})$. Right panel: The region and primers utilized in ChIP. (B) ChIP analyses with K562 cells (left) and primary erythroid cells (right). Top 2 rows: ChIP with antibodies against $\mathrm{DiAcH} 3$ and H3K4me2. Third row and left panel of fourth row: ChIP with antibodies against $\mathrm{H} 3 \mathrm{~K} 27 \mathrm{me} 3$ and $\mathrm{H} 3 \mathrm{~K} 9 \mathrm{me} 3$. For $\mathrm{H} 3 \mathrm{~K} 27$ me3, a region of the HoxB7 gene was included as a positive control, and a region of the $\beta$-actin promoter was included as negative control. For H3K9me3, a region of hsSat2, repeat F1-X72636, was included as a positive control, and a region of the actin promoter was included as negative control. Bottom right panels: The region and primers utilized in ChIP.

in the regions $5^{\prime}$ to $5^{\prime} \mathrm{HS}$, between $5^{\prime} \mathrm{HS}$ and $3^{\prime} \mathrm{HS} 1 / 3^{\prime} \mathrm{HS} 2$, and $3^{\prime}$ to $3^{\prime} \mathrm{HS} 2$. In chromatin from erythroid K562 cells, the regions upstream of 5'HS and downstream of $3^{\prime} \mathrm{HS} 2$ contained no DNase I HS and were resistant to DNase I digestion, similar to the inactive keratin locus (Supplemental Figure 2). In contrast, the region between $5^{\prime} \mathrm{HS}$ and $3^{\prime} \mathrm{HS} 1$ was sensitive to DNase I digestion (Supplemental Figure 2). Similar studies were performed with neural, T lymphocyte, epithelial, and embryonic kidney cell chromatin. In all nonerythroid cell nuclei, all 3 regions were resistant to DNase I digestion (Supplemental Figure 3 and data not shown). These data indicate that the region between $5^{\prime} \mathrm{HS}$ and $3^{\prime} \mathrm{HS} 1$ exhibits generalized DNase I sensitivity in erythroid cells, correlating with the erythroid-specific expression of ankyrin $1 \mathrm{E}$.

The 5'HS region exhibits functional characteristics of an insulator with barrier activity. Barrier insulators protect against position effect variegation (PEV), the stochastic, stable, heritable silencing of a euchromatic gene via spreading of heterochromatin. A gene silencing/PEV assay was utilized to determine whether the region containing the ankyrin $5^{\prime} \mathrm{HS}$ has barrier insulator activity $(29,30)$. A plasmid containing the HS2 enhancer from the $\beta$-globin locus control region, the human $\beta$-globin gene promoter, and an enhanced GFP reporter gene (HS2- $\beta$-globin-GFP; negative control) was cotransfected with a neomycin resistance gene into K562 cells and cultured under G418 selection $(29,31)$. Despite the presence of a strong enhancer, 0 of 12 clones containing the HS2- $\beta$-globin-GFP cassette expressed GFP, as all clones were silenced within 21 days (Figure 2). As shown previously, when the HS2- $\beta$-globin-GFP cassette was flanked with cHS4 (positive control), 12 of 12 lines expressed GFP in $100 \%$ of cells for more than 16 weeks (refs. 29, 32, and Figure 2 ). Flanking the HS2- $\beta$-globin-GFP cassette with 1 copy of the wild-type ankyrin $5^{\prime} \mathrm{HS}$ region, 2 copies of the wild-type ankyrin $5^{\prime} \mathrm{HS}$ region, or 4 copies of the wild-type ankyrin $5^{\prime} \mathrm{HS}$ region led to GFP expression in $100 \%$ of cells in 12 of 12,12 of 12 , and 11 of 12 cell lines, respectively, for more than 16 weeks (Figure 2). An HS2- $\beta$-globin-GFP cassette flanked with 2 copies of ankyrin 5 'HS containing a mutation of the GATA1 site that completely abolishes ankyrin promoter activity (8) led to GFP expression in 12 of 12 cell lines, indicating that the GATA1 site mutation had no influence on barrier element function in this assay.

The effect of the $-108 /-153$ ankyrin mutations on barrier function was examined in the same gene silencing/PEV assay. When the HS2$\beta$-globin-GFP cassette was flanked with 2 copies of the ankyrin $5^{\prime} \mathrm{HS}$ region containing the $-108 /-153$ mutations, GFP was expressed in only 6 of 12 lines after 21 days and only 2 of 12 lines after 16 weeks $\left(\chi^{2}=6.0, P<0.02\right.$ vs. wild-type; Figure 2$)$. We conclude that the ankyrin $5^{\prime} \mathrm{HS}$ region acts as a barrier insulator in erythroid cells and that the $-108 /-153$ mutations perturb this barrier function.

The ankyrin 5'HS region does not function as an insulator with enhancerblocking activity. Some insulators, such as the Drosophila gypsy insulator, the mouse SINE insulator, and the chicken HS4 insulator, include regions that confer the ability to act as an enhancer blocker when placed between an enhancer and a promoter, an activity associated with the binding of the 11-zinc finger protein CTCF $(30,33,34)$. In cHS4, barrier and enhancer blocker activities are clearly separable $(12,29,35-43)$. To determine whether the wildtype ankyrin $5^{\prime} \mathrm{HS}$ has enhancer-blocking activity, we used ankyrin $5^{\prime} \mathrm{HS}$, or cHS4 (positive control), to separate the mouse $\beta$-globin HS2 enhancer (44) or the GATA-1 enhancer (45) from a neomycin resistance gene linked to a $\gamma$-globin promoter. In the absence of intervening sequences, both HS2 and GATA-1 enhancers promoted the growth of numerous G418-resistant colonies (Figure 3). As shown previously, the cHS4 insulator suppressed this activity (46). The ankyrin -282 to $-1015^{\prime}$ HS region could not block the effects of either the mouse $\beta$-globin HS2 or GATA- 1 enhancer elements (Figure 3, A and B). These data indicate that the ankyrin 5 'HS region lacks enhancer-blocking activity in erythroid cells.

$5^{\prime} H S$ does not function as an erythroid promoter in reporter gene assays. Barrier insulators are frequently tightly associated with gene promoters, as evidenced by studies in model organisms (34, 47-49). Technical limitations of the ChIP assay preclude precise delineation of barrier and promoter function. To investigate whether ankyrin $5^{\prime} \mathrm{HS}$ possesses functional promoter activity as determined by its ability to direct expression of a linked reporter gene in cultured mammalian cells, we created a plasmid, $5^{\prime}$ HSAnkE, containing a 190-bp ankyrin 5'HS fragment upstream of a luciferase reporter gene. When $\mathrm{p} 5$ 'HSAnkE was transiently transfected into K562 cells, the relative luciferase activity 48 hours after transfection was equivalent to background $(0.98 \pm 0.88)$ similar to a promoterless pGL2b luciferase plasmid $(1.0 \pm 0.78)$. This is in contrast to luciferase activity directed by $\mathrm{p} 296$, a 271-bp minimal ankyrin erythroid promoter fragment upstream of a luciferase reporter gene (39.4 \pm 6.0$)(8)$ and pGL2P, a positive control plasmid with the SV40 early promoter directing a luciferase reporter gene $(66.3 \pm 12.4)$. Thus, the ankyrin 5 HS does not function as a promoter in reporter gene assays.

The ankyrin 5'HS region has the chromatin architecture of a barrier insulator. Insulators conferring barrier function and protection against PEV in model organisms are typically associated with posttranslational histone modifications associated with active chromatin, including high levels of histone acetylation and high levels of methylation of histone H3 lysine 4 (20, 26, 27, 29, 50). These histone modifications were examined in the ankyrin $5^{\prime} \mathrm{HS}$ region by quantitative ChIP analyses in K562 cells. Consistent with prior observations, the chromatin around ankyrin 5'HS had significant levels of histone $\mathrm{H} 3$ and $\mathrm{H} 4$ acetylation (Figure 4A, left panel). In addition, there was significant histone $\mathrm{H} 3$ mono-, di-, and trimethylation of the lysine 4 residue (Figure 4A, middle panel) in the $5^{\prime} \mathrm{HS}$ region in erythroid cells. These data indicate that the ankyrin $5^{\prime} \mathrm{HS}$ region, like the cHS4 barrier, is a site of active chromatin remodeling in erythroid cells.

To determine the chromatin status of the extended regions flanking $5^{\prime} \mathrm{HS}$ and $3^{\prime} \mathrm{HSs}$, ChIP analyses were performed in K562 cells. Two histone modifications typically associated with active chromatin, diacetylation of histone $\mathrm{H} 3(\mathrm{DiAcH} 3)$ and dimethylation 

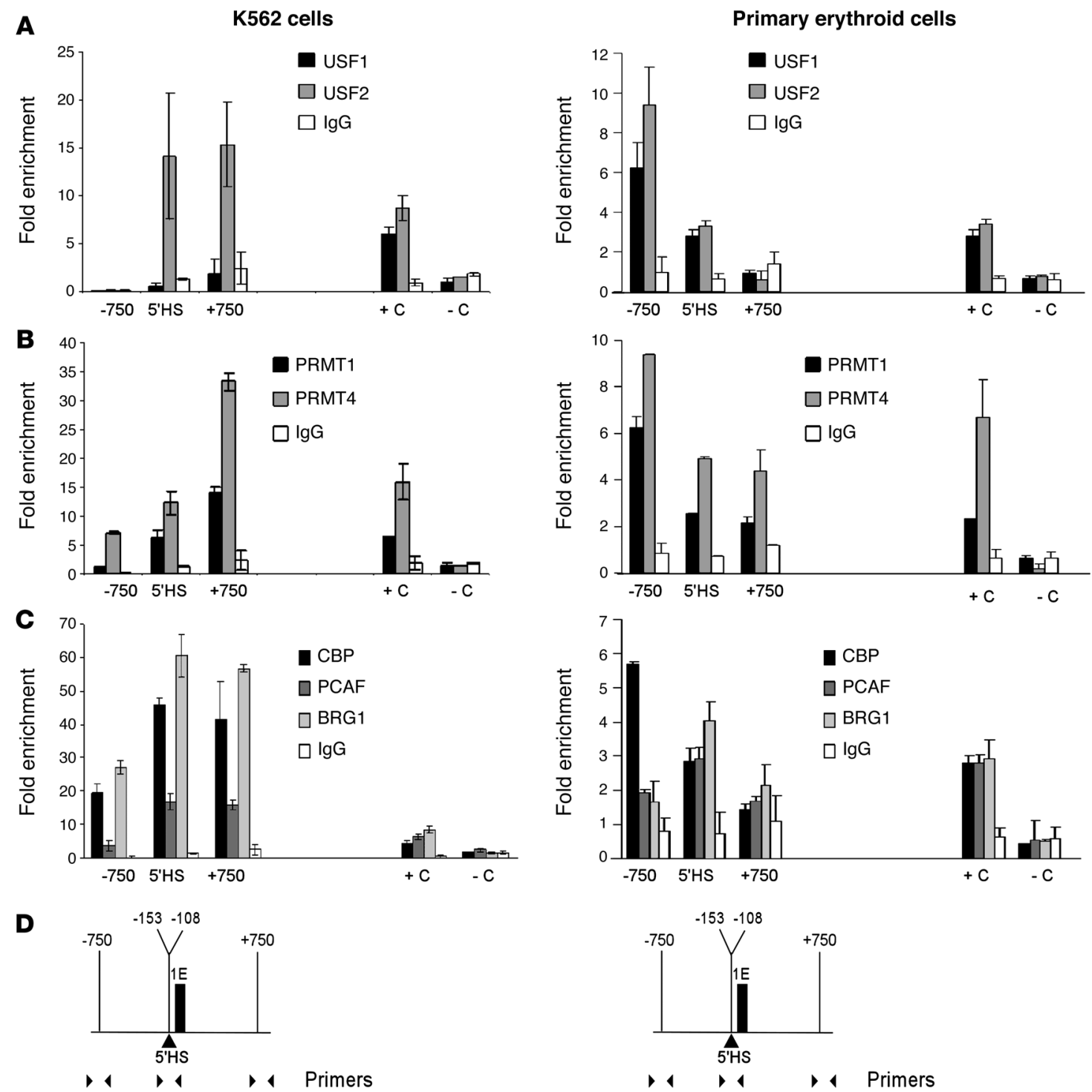

Figure 5

Quantitative ChIP analyses of barrier-associated protein occupancy in the ankyrin-1 5'HS region. Quantitative ChIP studies were performed to examine barrier-associated protein occupancy in the ankyrin $5^{\prime} \mathrm{HS}$ region using K562 cell (left) and primary erythroid cell (right) chromatin. (A) ChIP analyses of the ankyrin 5'HS region using antibodies against USF1 and USF2. HS2 of the locus control region of the human $\beta$-globin locus was included as a positive control (93), and a region of the hsSat2 (94) was included as a negative control. (B) Methyltransferases. ChIP analyses of the ankyrin $5^{\prime} H S$ region using antibodies against PRMT1 and PRMT4. A region of the CITED2 gene promoter (95) was included as a positive control, and a region of the hsSat2 was included as a negative control. (C) Histone acetylases and chromatin remodeling proteins. ChIP analyses of the ankyrin 5'HS region using antibodies against CBP, PCAF, and SMARCA4/BRG1. A region of the IL4 gene promoter was included as a positive control (+C) for CBP, PCAF, and SMARCA4 (96), and a region of the hsSat2 was included as a negative control $(-C)$ for all 3 antibodies. (D) The region and primers utilized in ChIP.

of histone $\mathrm{H} 3$ lysine 4 (H3K4me2); and two histone modifications typically associated with inactive chromatin, trimethylation of histone 3 lysine 27 (H3K27me3) and trimethylation of histone 3 lysine 9 (H3K9me3). The $5^{\prime} \mathrm{HS}$ region was again shown to be a site of active chromatin remodeling, with significant levels of histone $\mathrm{H} 3$ acetylation and histone $\mathrm{H} 3 \mathrm{~K} 4$ dimethylation (Figure 4B, left column) without any enrichment of histone H3 K27 trimethylation or histone H3 K9 trimethylation. The extended regions flanking 5'HS lacked histone H3 acetylation and histone H3 K4 dimethylation, with enrichment for histone $\mathrm{H} 3 \mathrm{~K} 27$ trimethylation and histone H3 K9 trimethylation (Figure 4B, left column).
Chromatin architecture of ankyrin $5^{\prime} \mathrm{HS}, 3^{\prime} \mathrm{HSs}$, and flanking regions was also examined in cultured human primary erythroid cells. The $5^{\prime} \mathrm{HS}$ region was a site of active chromatin remodeling, with significant levels of histone $\mathrm{H} 3$ acetylation and histone H3 K4 dimethylation (Figure 4B, right column, $P<0.01$ ) without any enrichment of histone H3 K27 trimethylation. The extended region 5' of 5'HS lacked histone $\mathrm{H} 3$ acetylation and histone $\mathrm{H} 3 \mathrm{~K} 4$ dimethylation, with the region 3' of 3'HSs demonstrating only slight enrichment for histone H3 acetylation and histone H3 K4 dimethylation. Similar to K562 cell chromatin, there was significant $\mathrm{H} 3 \mathrm{~K} 27 \mathrm{me} 3$ enrichment in the region upstream of $5^{\prime} \mathrm{HS}$ (Figure $4 \mathrm{~B}$, right column, $P<0.01$ ). Thus, 

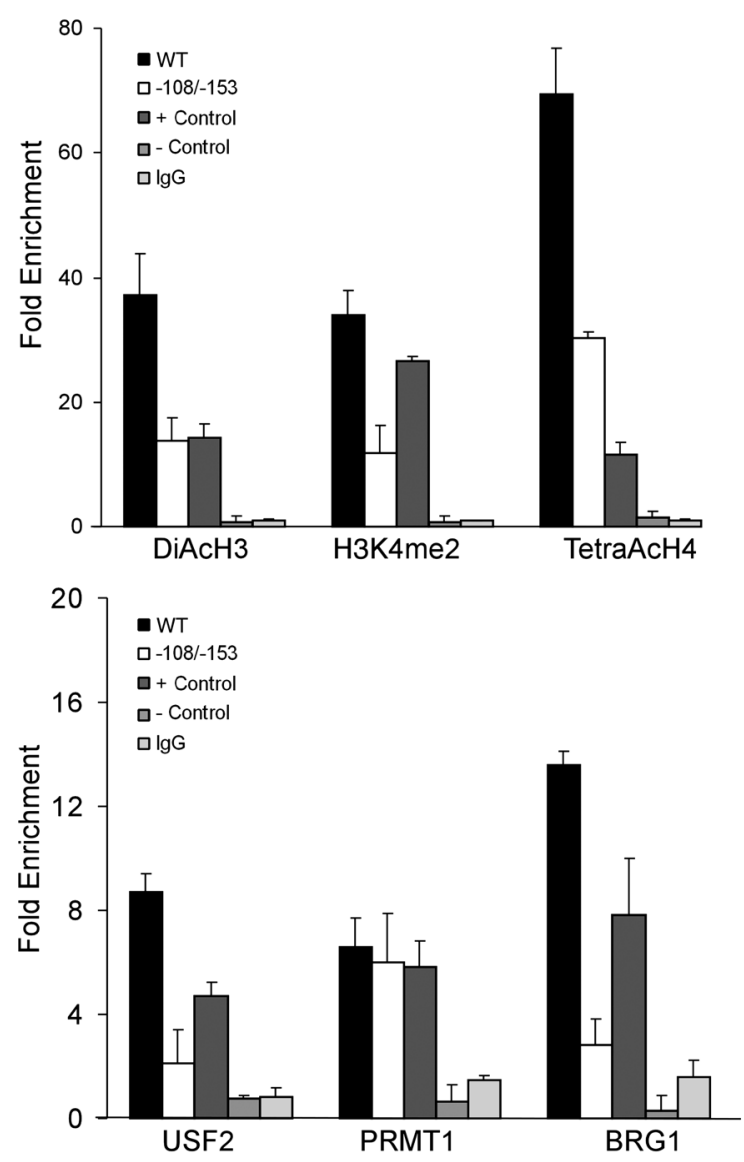

the chromatin architecture at 5'HS in both K562 cells and primary erythroid cells is consistent with that associated with barrier insulators, including high levels of histone acetylation and high levels of methylation of histone H3 lysine 4 (20, 26, 27, 29, 50).

The ankyrin 5'HS region binds barrier-associated proteins in vivo. One model of the cHS4 barrier insulator has upstream stimulatory factor (USF) proteins recruiting histone methyltransferase activity, histone acetyltransferases, ATP-dependent nucleosome remodeling complexes $(36,51,52)$, and other proteins to block the mechanism(s) that allow spreading of gene silencing-associated chromatin alterations into regions of active chromatin $(12,52)$. To determine whether the ankyrin $5^{\prime} \mathrm{HS}$ region exhibited similar characteristics, ChIP analyses were performed on K562 chromatin. USF2 (Figure 5A, left panel)

\section{Figure 6}

Chromatin architecture and barrier-associated protein binding are perturbed in ankyrin-1 5' HS -108/-153 cell lines. ChIP analyses of the ankyrin $5^{\prime} \mathrm{HS}$ region. Chromatin was isolated from 5 lines carrying single copies of the wild-type ankyrin $5^{\prime} \mathrm{HS}$ region flanking the HS2- $\beta$-globin-EGFP reporter gene and 5 cell lines carrying single copies of the ankyrin 5'HS region with $-108 /-153$ mutations flanking the HS2- $\beta$-globin-EGFP reporter gene. $-108 /-153$ lines were studied 3-5 weeks after transfection while still expressing GFP. Top: ChIP analyses of histone $\mathrm{H} 3$ and $\mathrm{H} 4$ acetylation and histone H3 K4 dimethylation in wild-type and -108/-153 mutant chromatin. Positive control, HS2 of the $\beta$-globin locus; negative control, a region from hsSat2. Lines with the mutant transgene showed a significant decrease in the level of $\mathrm{H} 3$ and $\mathrm{H} 4$ acetylation and $\mathrm{H} 3 \mathrm{~K} 4$ dimethylation over 5'HS. Bottom: ChIP analyses of USF2, PRMT1, and BRG1 occupancy in wild-type and $-108 /-153$ mutant chromatin. Positive control, HS2 of the $\beta$-globin locus; negative control, a region from hsSat2. Mutant lines showed a significant decrease in the level of USF2 and BRG binding.

\section{Table 1}

Ankyrin promoter/Ay-globin transgene expression

\begin{tabular}{|c|c|c|c|c|c|}
\hline Transgene Name & $\begin{array}{l}\text { No. lines with } \\
\text { copy no. } \leq 10\end{array}$ & $\begin{array}{l}\text { No. lines expressing } \\
\text { transgene }\end{array}$ & $\begin{array}{c}\text { Mean }{ }^{A} \gamma \text {-globin/ } \\
\text { murine } \alpha \text {-globin mRNA } \\
\text { per transgene }\end{array}$ & $\begin{array}{l}\text { No. lines with uniform } \\
\text { Y-globin protein expression } \\
\text { copy number }\end{array}$ & $\begin{array}{l}\text { No. lines with } \\
\text { variegated } \\
\text { expression }\end{array}$ \\
\hline$-296 \mathrm{WT} / \mathrm{A}_{\gamma}$ & 14 & 14 & $0.044 \pm 0.014$ & $8 / 8$ & $0 / 8$ \\
\hline-650 WT/A $\gamma$ & 6 & 6 & $0.048 \pm 0.026$ & $6 / 6$ & $0 / 6$ \\
\hline$-2270 \mathrm{WT} / \mathrm{A}_{\gamma}$ & 5 & 5 & $0.042 \pm 0.008$ & $5 / 5$ & $0 / 5$ \\
\hline-296 mutant $-108 /-153 / \mathrm{A}_{\gamma}$ & 11 & 6 & $0.015 \pm 0.019$ & $2 / 6$ & $4 / 6$ \\
\hline $\begin{array}{l}\text { cHS4-296 mutant } \\
-108 /-153 / A_{y}-\mathrm{cHS} 4\end{array}$ & 7 & 7 & $0.045 \pm 0.013$ & $7 / 7$ & $0 / 7$ \\
\hline
\end{tabular}


A -296 Mutant $-108 /-153 / A_{y}$ Transgene

\begin{tabular}{|c|c|c|c|}
\hline $\begin{array}{c}-108 /-153 \\
\text { Ank 1E } \\
\end{array}$ & Exon 1 & Exon 2 & Exon 3 \\
\hline
\end{tabular}

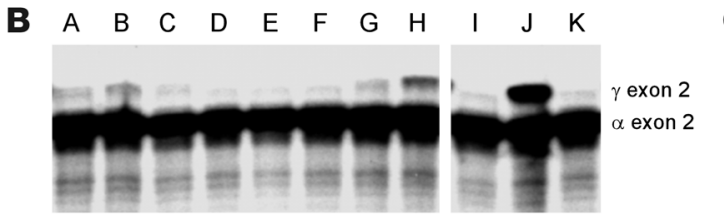

\section{Figure 7}

The mutant ankyrin-1 -108/-153 phenotype in vivo. Mice with mutant $-108 /-153$ ankyrin promoter transgenes. (A) Transgene. Transgenic mice were created with a mutant $-108 /-153$ ankyrin erythroid promoter/human $\gamma$-globin reporter gene cassette (-296 mutant $\left.-108 /-153 / \mathrm{A}_{\gamma}\right)$ and compared with previously described wild-type ankyrin erythroid promoter/human $\gamma$-globin reporter transgenic mice (10). (B) Detection of $A_{\gamma}$-globin mRNA in reticulocytes of transgenic mice. RNA from adult reticulocytes was hybridized to ${ }^{32} \mathrm{P}$-labeled antisense riboprobes for the human $A_{\gamma}$-globin gene (top band) and the mouse $\alpha$-globin gene (lower band) and digested with RNase. Protected fragments were separated by PAGE followed by radiography. Transgenic lines are indicated by letters above the lanes corresponding to Table 2. (C) Correlation of transgene copy number with the levels of A $\gamma$-globin mRNA. For comparison, as previously published (10), linear regression analysis of the transgene copy number with the corrected mRNA expression level was performed with wild-type -296 WT/A $y$ mice and -296 mutant $-108 /-153 / A_{\gamma}$ mice. There was a linear relationship in -296 WT/ $A_{\gamma}$ mice, indicating copy number-dependent expression (10). There was no relationship in -296 mutant $-108 /-153 / A_{\gamma}$ mice, indicating copy number-independent expression.

The binding of barrier-associated proteins to the $5^{\prime} \mathrm{HS}$ region was also assessed in cultured human primary erythroid cells. In contrast to K562 cells, both USF1 and USF2 occupied the 5'HS region in primary erythroid cells (Figure $5 \mathrm{~A}$, right panel). Occupancy by the protein arginine $N$-methyltransferase proteins PRMT1 and PRMT4 and the histone acetyltransferases $\mathrm{CBP}$ and PCAF was found in the 5'HS region (Figure 5, B and C, right panels). Occupancy by BRG1/ SMARCA4 was also found in the $5^{\prime} \mathrm{HS}$ region in chromatin from primary erythroid cells. We conclude that the complex found in the ankyrin $5^{\prime} \mathrm{HS}$ region has many proteins in common with the complexes associated with the cHS4 barrier insulator (52).

Chromatin architecture is perturbed in -108/-153 ankyrin 5'HS erythroid cell lines. West and colleagues have previously demonstrated that levels of histone modifications at transgenic insulators are comparable to those observed for the endogenous 5' cHS4 insulator and that artificial mutations in the cHS4 barrier insulator cause a reduction in histone acetylation $(29,36)$. We performed ChIP analysis of histone $\mathrm{H} 3$ acetylation, histone $\mathrm{H} 4$ acetylation, and histone $\mathrm{H} 3 \mathrm{~K} 4$ dimethylation in chromatin extracted from wild-type and mutant -108/-153 ankyrin/GFP cell lines from the gene silencing/PEV assay (Figure 2). In contrast to cell lines with the wild-type ankyrin 5'HS/GFP transgene, cell lines with the mutant $-108 /-153$ ankyrin 5' HS/GFP transgene showed a significant decrease in the level of $\mathrm{H} 3$ acetylation, $\mathrm{H} 4$ acetylation, and $\mathrm{H} 3 \mathrm{~K} 4$ dimethylation over the 5 ' $\mathrm{HS}$ region (DiAcH3: $P<0.007$, TetraAcH4: $P<0.008$, and H3K4me2: $P<0.006$; Figure 6 , top panel). These data indicate the $-108 /-153$ mutations are associated with altered chromatin configuration.
Barrier-associated protein binding is perturbed in -108/-153 ankyrin 5'HS erythroid cell lines. We took advantage of previous observations that mutations in transgenic barrier insulators lead to alterations that are comparable to those observed for the endogenous insulator $(29,36)$ to study the binding of barrier-associated proteins in stably transfected wild-type and -108/-153 mutant ankyrin 5'HS/GFP cell lines. There was significantly decreased binding of the barrier-associated proteins USF2 and BRG1 in chromatin extracted from mutant -108/-153 ankyrin/ GFP cell lines compared with wild-type (USF2: $P<0.002$ and BRG1: $P<0.001$; Figure 6 , bottom panel). There was no difference in binding of PRMT1 or PRMT4 (data not shown) between wild-type and mutant $-108 /-153$ ankyrin/GFP cell lines.

The wild-type ankyrin erythroid promoter is sufficient for uniform, copy number-dependent, position-independent expression in transgenic mice. We have previously shown that transgenic mice with the wild-type minimal ankyrin erythroid promoter ( -296 to -15 , including the $5^{\prime} \mathrm{HS}$ region $\left[-296 \mathrm{WT} /{ }^{\mathrm{A}} \gamma\right]$; Supplemental Figure 4) linked to a $\gamma$-globin reporter gene demonstrate uniform, copy number-dependent, position-independent $\gamma$-globin expression in erythroid cells, consistent with barrier function. To determine whether the regions upstream of 5 'HS had any influence of the level of transgene expression, we generated additional transgenic mouse lines (Supplemental Figure 4) containing ankyrin promoter sequences from -15 to -650 ( 6 lines, $-650 \mathrm{WT} /{ }^{\mathrm{A}} \gamma$ ) and -15 to $-2.7 \mathrm{~kb}$ (5 lines, $\left.-2700 \mathrm{WT} /{ }^{\mathrm{A}} \gamma\right)$. All of these transgenic lines demonstrated uniform, position-independent expression of $\gamma$-globin at levels that were identical to those of mice containing the minimal ankyrin erythroid promoter (significant correlation between transgene copy number and the level of $\gamma$-globin mRNA, $r^{2}=0.6612-0.9629$, $P=0.05-0.0001$; Table 1 ), indicating that no additional regulatory elements are located upstream of the ankyrin $5^{\prime} \mathrm{HS}$.

In contrast, analysis of 11 lines of transgenic mice, 6 from our previous study (10) and 5 additional lines generated for this study, with mutant $-108 /-153$ minimal ankyrin erythroid promoters linked to a human $\gamma$-globin reporter gene (-296 mutant $-108 /-153 /{ }^{A} \gamma$, Figure $7 A$ ), exhibited position-dependent (5 of 11 lines are silent), nonuniform or variegated expression (4 of 6 expressing lines, $\left.r^{2}=0.08, P>0.8\right)$ of $\gamma$-globin at levels that were significantly lower than those of wild-type mice $(0.015 \% \pm 0.019 \%$ vs. $0.44 \% \pm 1.4 \%$ of $\alpha$-globin mRNA/transgene copy, $P<0.0019$; Table 2 and Figure 7, B and C). Analysis of the transcriptional start sites indicated that wild-type and -296 mutant $-108 /-153 /{ }^{A} \gamma$ transgenic mice used the same 4 identical RNA transcription start sites, corresponding to sites 1,2,3, and 4, previously identified in erythroid cell RNA (Supplemental Figure 5) in identical ratios (55). These data confirm that decreased $\gamma$-globin expression directed by the $-108 /-153$ erythroid promoter cassette was not due to alterations in start site utilization. 


\section{Table 2}

Expression of A $\gamma$-globin in -296 mutant $-108 /-153 / A_{y}$ transgenic mice

$\begin{array}{lc}\text { Transgenic } & \begin{array}{c}\text { Transgene copy } \\ \text { number }\end{array} \\ \text { line }^{1} & \text { number }\end{array}$

$\begin{array}{cc}\text { A } & 1 \\ B & 3 \\ \text { C } & 2 \\ D & 1 \\ \text { E } & 3 \\ F & 4 \\ \text { G } & 4 \\ H & 10 \\ \text { I } & 8 \\ \text { J } & 6 \\ \text { K } & 5\end{array}$

Mean

\section{Y-Globin mRNA/ murine $\alpha$-globin mRNA ${ }^{2}$}

$0.015 \pm 0.011$
$0.016 \pm 0.009$
$0.011 \pm 0.005$
$0.005 \pm 0.002$
$0.008 \pm 0.002$
$0.007 \pm 0.002$
$0.018 \pm 0.004$
$0.048 \pm 0.011$
$0.004 \pm 0.003$
$0.27 \pm 0.084$
$0.005 \pm 0.002$

${ }^{1}$ Previously reported animals are lines A-G (10). Additional animals generated for this study are lines H-K. ${ }^{2}$ Relative $\gamma$-globin mRNA levels of 0.01 and lower are indistinguishable from background. Thus, $\gamma$-globin protein was unable to be assessed, indicated by ND (not done).

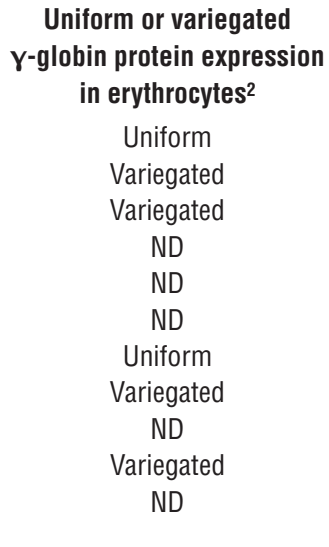

The chicken HS4 barrier insulator rescues the -108/-153 mutant phenotype in transgenic mice. Transgenic studies in both Drosophila and mice have used barrier insulators to flank reporter genes to prevent gene silencing and reduce PEV in vivo (22, 23, 29, 30, $32,35,46,56-61)$. Based on the data above, we hypothesized that the $-108 /-153$ spherocytosis-associated mutations disrupt the barrier activity of $5^{\prime} \mathrm{HS}$, leading to perturbations in ankyrin gene expression in erythroid cells, and this defect would be corrected by flanking the mutant $-108 /-153$ erythroid promoter/ $\gamma$-globin transgene with the well-defined cHS4 insulator (Figure 8A; cHS4-296 mutant $-108 /-153 /{ }^{A} \gamma$ cHS4). To test this hypothesis, we generated 7 lines of cHS4-296 mutant -108/-153/A $\gamma$ cHS4 transgenic mice.

RNase protection demonstrated that 7 of $7 \mathrm{cHS} 4-296$ mutant $-108 /-153 /{ }^{A} \gamma$ cHS 4 transgenic lines expressed mRNA from ${ }^{A} \gamma$-globin gene in adult erythroid cells (reticulocytes) (Figure $8 \mathrm{~B}$ and Table 3 ), indicating position-independent expression. cHS4-296 mutant $-108 /-153 /{ }^{A} \gamma$ cHS 4 transgenic mice had mean levels of ${ }^{A} \gamma$-globin mRNA of approximately $0.45 \%$ per mouse $\alpha$-globin mRNA/transgene copy, identical to that of mice with the wild-type erythroid promoter $/ \gamma$-globin transgene $(P=0.877$; Figure 8B and Table 3$)$. Mice with the cHS4-296 mutant $-108 /-153 /{ }^{A} \gamma$ cHS4 transgene expressed the ${ }^{A} \gamma$-globin transgene in a copy number-dependent fashion (copy number correlation with $\gamma$-globin mRNA level, $r^{2}=0.94, P<0.001$; linear relationship; Figure $8 \mathrm{C}$ ). Similar to transgenic mice with the wild-type promoter, all 7 lines of cHS4-296 mutant -108/-153/A $\gamma$ cHS4 transgenic mice expressed human $\gamma$-globin in a uniform pattern, i.e., in $100 \%$ of erythrocytes (Tables 1 and 3 and Figure $8 D$ ). Flanking the $-108 /-153$ mutant erythroid promoter with cHS4 completely rescued the defects associated with the mutant $-108 /-153$ phenotype.

\section{Discussion}

The focus of our studies was to determine the mechanism by which the $-108 /-153$ ankyrin upstream erythroid promoter region mutations exert their influence on ankyrin gene expression in erythroid cells. Previous in vitro reporter gene assays revealed no differences between wild-type and mutant -108/-153 promoters, while $-108 /-153$ mutant ankyrin promoter $/ \gamma$-globin reporter transgenic mouse assays revealed perturbed $\gamma$-globin expression (10). Together, these data indicated that intact chromatin was necessary to manifest the promoter mutations and led to the hypothesis that this region functions as a barrier insulator. The data presented here indicate that the ankyrin $5^{\prime} \mathrm{HS}$ region is a barrier insulator in erythroid cells. In addition to the erythroid promoter, there are at least three other ankyrin-1 promoters, one approximately $40 \mathrm{~kb} \mathrm{5}$ of the erythroid promoter directing transcripts in neural and muscle cells, one approximately $16 \mathrm{~kb}$ $3^{\prime}$ of the erythroid promoter directing transcripts in cerebellar cells, and one approximately $200 \mathrm{~kb} \mathrm{3}$ ' of the erythroid promoter directing transcripts in skeletal muscle (62-66). Thus, it is not surprising that tissue-specific barrier insulators are required in the ankyrin-1 locus to prevent ectopic expression or silencing of tissue-specific transcripts. We propose a model of ankyrin-1 gene regulation that includes the $5^{\prime} \mathrm{HS}$ region acting as a barrier insulator, engaging numerous proteins including USFs that recruit PRMTs, CBP, and P300, SMARCA4, and other unidentified chromatin remodeling-associated proteins to protect the erythroid promoter region and exon $1 \mathrm{E}$ from encroachment of heterochromatin in erythroid cells.

Identification of a barrier insulator near the ankyrin gene erythroid promoter is not surprising. Several recent studies have revealed numerous similarities between barrier insulators and promoters, including similar chromatin architecture, subnuclear localization, and binding of specific transcription factors (67-71). Based on growing evidence, one emerging hypothesis proposes that barrier insulators evolved as specialized derivatives of gene promoters, each with specific, yet discrete function $(34,70,71)$.

Identifying the mechanisms of barrier insulator activity in mammalian cells is fundamental to our understanding of gene regulation. However, our understanding of the structure and function of barrier insulators in mammalian cells is limited. Much of the data available on barrier insulators have come from model organisms, particularly yeast and Drosophila $(20,22,25,71)$. Mutagenesis or deletion of various barrier/boundary-associated 
A cHS4-296 mutant $-108 /-153 /{ }^{\mathrm{A}} \gamma$ cHS4 transgene

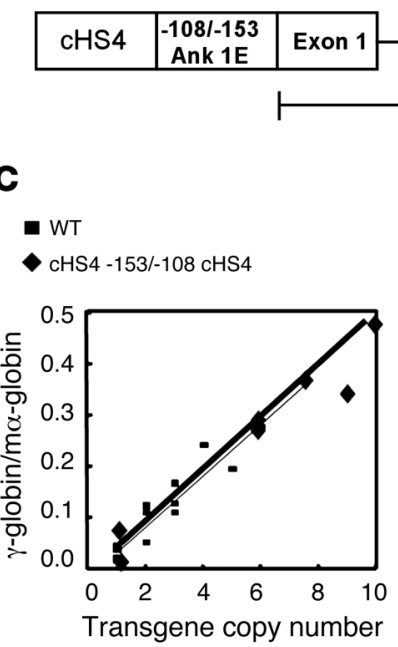

B $A \begin{array}{lllllllll} & \text { C } & D & E & F & G & \text { Transgenic line }\end{array}$

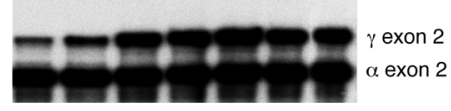

Figure 8

Rescue of the mutant ankyrin-1 -108/-153 phenotype in vivo. The cHS4 barrier insulator rescues the mutant $-108 /-153$ phenotype, restoring position-independent, copy number-dependent, uniform expression to the mutant $-108 /-153$ ankyrin erythroid promoter transgene. (A) Transgenic mice with a mutant -108/-153 ankyrin erythroid promoter/human $\gamma$-globin reporter gene cassette flanked by the cHS4 insulator (cHS4-296 mutant $-108 /-153 / A_{\gamma}$ cHS4). (B) Detection of $A_{\gamma}$-globin mRNA in reticulocytes of transgenic mice using ${ }^{32}$ P-labeled riboprobes for the ${ }^{A_{\gamma}}$-globin gene (top band) and the mouse $\alpha$-globin gene (lower band). Transgenic lines are indicated with letters above the lanes corresponding to Table 3 . (C) Correlation of transgene copy number with the levels of Ay-globin mRNA. Linear regression analysis of transgene copy number with corrected mRNA expression level was performed with -296 WT/A $\gamma$ and cHS4-296 -108/-153/A $\gamma$ cHS4 mice. (D) Expression of $\gamma$-globin protein in erythrocytes of cHS4-296 mutant -108/-153/A $\gamma$ cHS4 transgenic mice using an FITC-conjugated antibody correlated with number of erythrocytes counted. Thick lines represent transgenic mice, and thin lines represent nontransgenic littermate controls. Single peaks represent uniform expression of $\gamma$-globin. Bimodal peaks represent nonuniform/variegated expression of $\gamma$-globin. Top panels show results from a control mouse with uniform (i.e., $100 \%$ of erythrocytes) $\gamma$-globin expression and a control with nonuniform/variegated expression, similar to that seen in -296 mutant -108/-153/A $\gamma$ transgenic mice (10). The bottom panels represent uniform expression in cHS4-296 mutant $-108 /-153 /{ } \gamma \mathrm{cHS} 4$ transgenic mice. Representative transgenic lines are shown, with the letters corresponding to Table 3.

genes or domains in model organisms allows spreading of heterochromatin across a boundary, silencing adjacent loci $(20,36$, $72,73)$, in a manner similar to the $-108 /-153$ mutations. Our data support the model according to which barrier insulators recruit enzymes and other proteins associated with activating histone modifications to block the mechanism(s) that lead to spreading of gene silencing-associated chromatin alterations into regions of active chromatin $(12,52)$. This is the first example to our knowledge to identify disruption of a barrier insulator as a pathogenetic mechanism of human disease.
Because of their essential roles in maintaining higher-order chromatin structure and regulating appropriate patterns of gene expression, mutation of barrier insulators likely plays an important role in the pathogenesis of numerous inherited and acquired diseases. We predict that perturbations in gene expression associated with acquired karyotypic alterations observed in malignant cellular transformation are in part due to altered barrier insulator structure and function $(74,75)$. These predictions are consistent with observations of disease phenotype associated with disruption or deletion of enhancer blocker insulators, such as myotonic

Table 3

Expression of Ay-globin in cHS4-296 mutant -108/-153/Ay-cHS4 transgenic mice

$\begin{array}{ccc}\text { Transgenic line } & \begin{array}{c}\text { Transgene copy } \\ \text { number }\end{array} & \begin{array}{c}\gamma \text {-Globin mRNA/ } \\ \text { murine } \alpha \text {-globin mRNA }\end{array}\end{array}$

$\begin{array}{cc}\text { A } & 1 \\ \text { B } & 1 \\ \text { C } & 8 \\ \text { D } & 10 \\ \text { E } & 9 \\ \text { F } & 6 \\ \text { G } & 6\end{array}$

Mean
$0.03 \pm 0.005$
$0.073 \pm 0.018$
$0.36 \pm 0.013$
$0.48 \pm 0.025$
$0.32 \pm 0.02$
$0.24 \pm 0.017$
$0.27 \pm 0.04$

$\begin{array}{cc}1 & 0.03 \pm 0.005 \\ 1 & 0.073 \pm 0.018 \\ 8 & 0.36 \pm 0.013 \\ 10 & 0.48 \pm 0.025 \\ 9 & 0.32 \pm 0.02 \\ 6 & 0.24 \pm 0.017 \\ 6 & 0.27 \pm 0.04\end{array}$

$\gamma$-Globin mRNA/
murine $\boldsymbol{\alpha}$-globin mRNA
per copy
0.032
0.073
0.045
0.048
0.035
0.040
0.045
$0.045 \pm 0.013$

Uniform or variegated
$\gamma$-globin protein expression in erythrocytes

Uniform

Uniform

Uniform

Uniform

Uniform

Uniform

Uniform 
dystrophy associated with loss of function of the DM1 enhancer blocker insulator (76) and chromosomal deletions, or translocations of regions containing CTCF-binding sites in Beckwith-Wiedemann syndrome, Wilms tumor, and various cancers (77). Thus, disruption of either barrier insulator or enhancer-blocking insulator function is expected to be a general mechanism associated with inherited and acquired genetic disease.

Advances in genomic technologies, particularly genome-wide association studies and functional genomics, are advancing our understanding of gene regulation and human disease $(78,79)$. Association studies have identified numerous disease-associated single nucleotide polymorphisms, most residing in noncoding regions of the genome. In parallel, functional genomics studies, such as ChIPbased assays, have allowed identification of regions of DNA with regulatory potential throughout the genome (80-83). Studies such as this report that localize and define in detail critical gene regulatory elements such as insulators are essential for our understanding of the mechanisms of inherited and acquired disease. Synthesis of the data obtained from these complementary lines of investigation is necessary to begin to unravel the complex mechanisms of genetic variation in disease-susceptibility loci (84).

\section{Methods}

Cell culture and selection. K562 cells (chronic myelogenous leukemia in blast crisis with erythroid characteristics, ATCC catalog CCL-243) were maintained in RPMI 1640 medium with 10\% fetal calf serum. Human CD34selected stem and progenitor cells were obtained from the Yale Center for Excellence in Molecular Hematology Cell Core and cultured in StemSpan SF expansion medium (StemSpan, 09650) with estradiol (100 ng/ml), dexamethasone $(10 \mathrm{ng} / \mathrm{ml})$, human transferrin $(200 \mathrm{ng} / \mathrm{ml})$, insulin $(10 \mathrm{ng} / \mathrm{ml})$, Flt3 ligand $(100 \mathrm{n} / \mathrm{ml})$, stem cell factor $(100 \mathrm{ng} / \mathrm{ml})$, IL-3 $(50 \mathrm{ng} / \mathrm{ml})$, IL-6 $(20 \mathrm{ng} / \mathrm{ml})$, insulin like growth factor- $1(50 \mathrm{ng} / \mathrm{ml})$, and erythropoietin $(3 \mathrm{U} / \mathrm{ml})$ for 9-14 days $(85,86)$. FACS analysis was used to analyze cellular expression of CD71 (transferrin receptor) and CD235a (glycophorin A). Magnetic bead selection for CD71 (MACS, 130-046-201) and CD235a (MACS, 130-050-501) was used to purify an R3/R4 population of erythroid cells (87).

Human $\mathrm{CD} 4^{+}$hematopoietic stem and progenitor cells were supplied by the Yale Center for Excellence in Molecular Hematology. The protocol for collection of these cells was approved by the Yale Human Investigation Committee, June 22, 2010 (HIC\# 0309025874).

DNase I HS mapping. DNase I HS mapping was performed as described previously $(88,89)$, with minor modifications. DNA was extracted from nuclei harvested from approximately $1 \times 10^{8}$ logarithmically growing K562 (erythroid), HeLa (epithelial-like), SH-SY5Y (neuroblastoma), Jurkat (T lymphocyte), or HEK 293 (embryonic kidney) cells and digested for Southern blot analysis. For fine mapping, the migration of the band generated by digestion with DNase I and the appropriate restriction enzyme was compared with the migration of bands generated by the double digestion of high-molecular-weight DNA with the appropriate restriction enzyme and other restriction enzymes.

Barrier insulator/PEV assays. Flanking promoter/reporter genes with insulators conferring barrier activity in vivo prevents gene silencing by protecting the transgene from PEV in long-term tissue culture assays (30, $33,57,90$ ). In barrier insulator assays (also known as gene silencing/PEV assays), variability in expression and extinction of reporter gene expression due to chromosomal position effects arising from the influence of insulators flanking the sites of transgene integration are assessed over time. In these assays, the barrier must flank both the $5^{\prime}$ and $3^{\prime}$ ends of the transgene, as randomly integrated constructs may experience heterochromatic-mediated gene silencing from either direction $(31,90)$. Test plasmids containing the enhanced GFP as reporter gene were cotransfected into K562 cells with a pRSV-neomycin plasmid. After selection, individual clones were isolated and expanded in G418-containing medium and switched to nonselective medium before analysis of GFP expression via fluorescence-activated cell sorting 21 days and 16 weeks later. Southern blot analysis was used to confirm that selected clones had an intact GFP construct. The negative control plasmid, HS2- $\beta$-GFP, consisted of the human $\beta$-globin HS2 enhancer, the human $\beta$-globin gene promoter, and the EGFP reporter gene. The positive control plasmid consisted of the HS2- $\beta$-GFP cassette flanked with HS4 from the chicken $\beta$-globin cluster locus control region (cHS4) insulator.

Enhancer-blocking assays. Enhancer-blocking activity was analyzed in a well-defined assay where insulators under study are assessed for their ability to act as an enhancer blocker when placed between an enhancer and a promoter (30). Ankyrin 5'HS sequences were used to separate the mouse $\beta$-globin HS2 locus control region enhancer (44) from a $\gamma$-globin promoter linked to a neomycin resistance gene. In the positive control plasmid, cHS4 sequences separated the HS2 enhancer from the $\gamma$-globin promoter-neomycin cassette. Plasmids were cotransfected with a neomycin resistance gene into $\mathrm{K} 562$ cells, plated in semisolid medium to allow growth of individual clones, and cultured under G418 selection for 2 weeks. Colony number was normalized to the number of colonies promoted by an HS2 $\gamma$-globin neomycin plasmid.

Reportergene assays. Plasmid $5^{\prime} \mathrm{HSAnkE}$ containing a 190-bp ankyrin $5^{\prime} \mathrm{HS}$ fragment upstream of a luciferase reporter gene was created by HindIII/Sma digestion of p296, a 271-bp minimal ankyrin erythroid promoter fragment upstream of a luciferase reporter gene (8), followed by a BmgBI/EcoRV (polylinker) digest and re-ligation to make a luciferase plasmid containing $5^{\prime} \mathrm{HS}$. This region includes the $181 \mathrm{bp} 5^{\prime}$ of the ankyrin promoter region between -282 to -101 mapped by DNase I HS mapping. Integrity of the plasmid was confirmed by sequencing. Test plasmids included $\mathrm{p} 5^{\prime} \mathrm{HSAnkE}$, p296, pGL2 basic, a promoterless negative control, and pGL2 promoter, a positive control plasmid containing an SV40 promoter directing expression of a firefly luciferase gene. pRLTK, a plasmid containing a herpes simplex virus thymidine kinase promoter directing a Renilla luciferase reporter gene (Promega), was used as an internal control reporter. All plasmids tested were purified using QIAGEN columns, and at least two preparations of each plasmid were tested in triplicate. $10^{7} \mathrm{~K} 562$ cells were transfected by electroporation with a single pulse of $300 \mathrm{~V}$ at 960 microfarad with $20 \mu \mathrm{g}$ of test plasmid and $1.0 \mu \mathrm{g}$ of pRLTK. Forty-eight hours after transfection, cells were harvested and lysed, the activity of both firefly and Renilla luciferase was determined in cell extracts, and the results were normalized.

Quantitative ChIP. ChIP analyses were performed as described previously (21). Antibodies used for immunoprecipitation were diacetylated histone H3 (Upstate Biotechnology, 06-599), tetraacetylated histone H4 (Upstate Biotechnology, 06-866), CBP (Santa Cruz Biotechnology Inc., A-22), histone $\mathrm{H} 3$ trimethylated lysine 27 (Abcam, ab6002), histone H3 trimethylated lysine 9 (Abcam, ab8893), histone H3 dimethylated lysine 4 (Abcam, ab7766), P300 (Santa Cruz Biotechnology Inc., C-20, SC-585X), USF1 (Santa Cruz Biotechnology Inc., H-86, sc-8983), USF2 (Santa Cruz Biotechnology Inc., C-20, sc-862), and Brg1/SMARCA4 (Santa Cruz Biotechnology Inc., H-88, SC-10768X). After elution and extraction, immunoprecipitated DNA was analyzed by quantitative real-time PCR (iCycler, Bio-Rad) using primers shown in Supplemental Table 1. Samples from at least 2 independent immunoprecipitations were analyzed each at least in triplicate as described. Parallel controls for each experiment included samples of no chromatin and nonimmune rabbit IgG. Positive and negative controls as described in the text and/or legends were also performed. Data are presented as mean \pm SEM of ChIP experiments. Statistical analyses were performed using GraphPad Prism version 2.0 software. 
Generation and analyses of transgenic mice. Construction of transgenes containing the wild-type -291 to -15 or the mutant $-108 /-153$ ankyrin erythroid promoters linked to a human $\gamma$-globin reporter gene has been described $(9,10)$. In a similar manner, wild-type -650 to -15 and wildtype -2700 to -15 ankyrin erythroid promoter $/ \gamma$-globin transgenes were constructed. The mutant $-108 /-153$ ankyrin erythroid promoter $/ \gamma$-globin cassette was flanked at the $5^{\prime}$ and $3^{\prime}$ ends by a $1.2-\mathrm{kb}$ XbaI fragment containing the cHS4 insulator (29). All plasmid constructs were sequenced to confirm that the appropriate ankyrin erythroid promoter was correctly fused to the ${ }^{\mathrm{A}} \boldsymbol{\gamma}$-globin gene.

Transgenic mice were generated and characterized as described previously $(9,91)$. Founder animals were identified by Southern blot analysis of DNA extracted from tail biopsies by probing with an ankyrin/A $\gamma$-globin probe. Ankyrin erythroid promoter/A $\gamma$-globin transgene expression in total cellular RNA extracted from adult reticulocytes was analyzed via RNase protection assay (RPA) using a riboprobe that contains sequences for both exon 2 of the human ${ }^{A} \gamma$-globin gene and exon 2 of the murine $\alpha$-globin gene, ensuring that the human ${ }^{A} \gamma$-globin and murine $\alpha$-globin sequences are labeled to equal specific activity, allowing direct comparison of human ${ }^{A} \gamma$-globin and murine $\alpha$-globin mRNA levels (10). Probe synthesis, hybridization, electrophoresis, autoradiography, and analyses were performed as described previously (10). At least 3 RNA samples per transgenic line were analyzed. Detection and measurement of $\gamma$-globin protein in erythrocytes of transgenic mice were performed as described $(21,92)$.

1. Eber S, Lux SE. Hereditary spherocytosis - defects in proteins that connect the membrane skeleton to the lipid bilayer. Semin Hematol. 2004;41(2):118-141.

2. Gallagher PG, Jarolim P. Red cell membrane disorders. In: Hoffman R, et al., eds. Hematology: Basic Principles and Practice. 5th ed. Philadelphia, Pennsylvania, USA: Elsevier Churchill Livingstone; 2008:chap 46.

3. Perrotta S, Gallagher PG, Narla M. Hereditary spherocytosis. Lancet. 2008;372(9647):1411-1426.

4. Gallagher PG. Hematologically important mutations: ankyrin variants in hereditary spherocytosis. Blood Cells Mol Dis. 2005;35(3):345-347.

5. Eber SW, et al. Ankyrin-1 mutations are a major cause of dominant and recessive hereditary spherocytosis. Nat Genet. 1996;13(2):214-218.

6. Miraglia del Giudice E, et al. Clinical and molecular evaluation of non-dominant hereditary spherocytosis. BrJ Haematol. 2001;112(1):42-47.

7. Leite RC, Basseres DS, Ferreira JS, Alberto FL, Costa FF, Saad ST. Low frequency of ankyrin mutations in hereditary spherocytosis: identification of three novel mutations. Hum Mutat. 2000;16(6):529.

8. Gallagher PG, Romana M, Tse WT, Lux SE, Forget BG. The human ankyrin-1 gene is selectively transcribed in erythroid cell lines despite the presence of a housekeeping-like promoter. Blood. 2000; 96(3):1136-1143.

9. Sabatino DE, et al. A minimal ankyrin promoter linked to a human gamma-globin gene demonstrates erythroid specific copy number dependent expression with minimal position or enhancer dependence in transgenic mice. J Biol Chem. 2000; 275(37):28549-28554.

10. Gallagher PG, et al. Erythrocyte ankyrin promoter mutations associated with recessive hereditary spherocytosis cause significant abnormalities in ankyrin expression. J Biol Chem. 2001; 276(45):41683-41689.

11. Valenzuela L, Kamakaka RT. Chromatin insulators. Annu Rev Genet. 2006;40:107-138.

12. Gaszner M, Felsenfeld G. Insulators: exploiting transcriptional and epigenetic mechanisms. Nat Rev Genet. 2006;7(9):703-713.

13. Kuhn EJ, Geyer PK. Genomic insulators: connecting properties to mechanism. Curr Opin Cell Biol.

The animal study protocol (\#G-97-4) was reviewed and approved by the National Human Genome Research Institute Animal Care and Use Committee, June 2010.

Statistics. $\chi^{2}$ and Pearson correlation coefficients were utilized for analyses of nominal variables with a Gaussian distribution. One-tailed Student's $t$ testing was utilized for comparing wild-type (nominal variable) and mutant (measurement variable) values. A $P$ value less than 0.05 was considered statistically significant. Data are presented throughout as mean \pm SEM.

\section{Acknowledgments}

Supported in part by NIDDK DK62039 (to P.G. Gallagher), HD000850 (to L.A. Steiner), and intramural funds from the National Human Genome Research Institute (to D.M. Bodine). The authors thank Bernard Forget, Yale University, for critical manuscript review.

Received for publication January 7, 2010, and accepted in revised form September 22, 2010.

Address correspondence to: Patrick G. Gallagher, Yale University School of Medicine, 333 Cedar Street, P.O. Box 208064, New Haven, Connecticut 06520-8064, USA. Phone: 203.688.2896; Fax: 203.785.6974; E-mail: patrick.gallagher@yale.edu. Or to: David M. Bodine, National Institutes of Health, 9000 Rockville Pike, Bldg 49, Room 4A04, Bethesda, Maryland 20892-0001, USA. Phone: 301.402.0902; Fax: 301.402.4929; E-mail: tedyaz@mail.nih.gov.

\section{3;15(3):259-265.}

14. Singh V, Srivastava M. Enhancer blocking activity of the insulator at H19-ICR is independent of chromatin barrier establishment. Mol Cell Biol. 2008;28(11):3767-3775.

15. Capelson M, Corces VG. Boundary elements and nuclear organization. Biol Cell. 2004;96(8):617-629.

16. Felsenfeld G, et al. Chromatin boundaries and chromatin domains. Cold Spring Harb Symp Quant Biol. 2004;69:245-250.

17. Gerasimova TI, Corces VG. Chromatin insulators and boundaries: effects on transcription and nuclear organization. Annu Rev Genet. 2001;35:193-208.

18. Labrador M, Corces VG. Setting the boundaries of chromatin domains and nuclear organization. Cell. 2002;111(2):151-154.

19. Zhou J, Berger SL. Good fences make good neighbors: barrier elements and genomic regulation. $\mathrm{Mol}$ Cell. 2004;16(4):500-502.

20. Oki M, Kamakaka RT. Barrier function at HMR. Mol Cell. 2005;19(5):707-716.

21. Gallagher PG, Nilson DG, Steiner LA, Maksimova YD, Lin JY, Bodine DM. An insulator with barrier-element activity promotes alpha-spectrin gene expression in erythroid cells. Blood. 2009 113(7):1547-1554.

22. Namciu SJ, Blochlinger KB, Fournier RE. Human matrix attachment regions insulate transgene expression from chromosomal position effects in Drosophila melanogaster. Mol Cell Biol. 1998; 18(4):2382-2391.

23. Zhong XP, Krangel MS. Enhancer-blocking activity within the DNase I hypersensitive site 2 to 6 region between the TCR alpha and Dad1 genes. J Immunol. 1999;163(1):295-300.

24. Farrell CM, West AG, Felsenfeld G. Conserved CTCF insulator elements flank the mouse and human betaglobin loci. Mol Cell Biol. 2002;22(11):3820-3831.

25. Oki M, Valenzuela L, Chiba T, Ito T, Kamakaka RT. Barrier proteins remodel and modify chromatin to restrict silenced domains. Mol Cell Biol. 2004;24(5):1956-1967.

26. Litt MD, Simpson M, Recillas-Targa F, Prioleau MN, Felsenfeld G. Transitions in histone acetylation reveal boundaries of three separately regulated neighboring loci. EMBO J. 2001;20(9):2224-2235.

27. Litt MD, Simpson M, Gaszner M, Allis CD, Felsenfeld G. Correlation between histone lysine methylation and developmental changes at the chicken betaglobin locus. Science. 2001;293(5539):2453-2455.

28. Steiner LA, et al. Chromatin architecture and transcription factor binding regulate expression of erythrocyte membrane protein genes. Mol Cell Biol. 2009;29(20):5399-5412.

29. Recillas-Targa F, et al. Position-effect protection and enhancer blocking by the chicken beta-globin insulator are separable activities. Proc Natl Acad Sci US A. 2002;99(10):6883-6888.

30. Chung JH, Whiteley M, Felsenfeld G. A 5' element of the chicken beta-globin domain serves as an insulator in human erythroid cells and protects against position effect in Drosophila. Cell. 1993;74(3):505-514.

31. Magis W, Fiering S, Groudine M, Martin DI. An upstream activator of transcription coordinately increases the level and epigenetic stability of gene expression. Proc Natl Acad Sci U S A. 1996;93(24):13914-13918.

32. Pikaart MJ, Recillas-Targa F, Felsenfeld G. Loss of transcriptional activity of a transgene is accompanied by DNA methylation and histone deacetylation and is prevented by insulators. Genes Dev. 1998;12(18):2852-2862.

33. Bell AC, West AG, Felsenfeld G. The protein CTCF is required for the enhancer blocking activity of vertebrate insulators. Cell. 1999;98(3):387-396.

34. Raab JR, Kamakaka RT. Insulators and promoters: closer than we think. Nat Rev Genet. 2010; 11(6):439-446.

35. West AG, Gaszner M, Felsenfeld G. Insulators: many functions, many mechanisms. Genes Dev. 2002;16(3):271-288.

36. West AG, Huang S, Gaszner M, Litt MD, Felsenfeld G. Recruitment of histone modifications by USF proteins at a vertebrate barrier element. Mol Cell. 2004;16(3):453-463.

37. Ramos E, Ghosh D, Baxter E, Corces VG. Genomic organization of gypsy chromatin insulators in Drosophila melanogaster. Genetics. 2006; 172(4):2337-2349. 
38. Markstein M, Pitsouli C, Villalta C, Celniker SE, Perrimon N. Exploiting position effects and the gypsy retrovirus insulator to engineer precisely expressed transgenes. Nat Genet. 2008;40(4):476-483.

39. Gdula DA, Gerasimova TI, Corces VG. Genetic and molecular analysis of the gypsy chromatin insulator of Drosophila. Proc Natl Acad Sci U S A. 1996;93(18):9378-9383.

40. Chung JH, Bell AC, Felsenfeld G. Characterization of the chicken beta-globin insulator. Proc Natl Acad Sci U S A. 1997;94(2):575-580.

41. Scott KC, Taubman AD, Geyer PK. Enhancer blocking by the Drosophila gypsy insulator depends upon insulator anatomy and enhancer strength. Genetics. 1999;153(2):787-798.

42. Sigrist CJ, Pirrotta V. Chromatin insulator elements block the silencing of a target gene by the Drosophila polycomb response element (PRE) but allow trans interactions between PREs on different chromosomes. Genetics. 1997;147(1):209-221.

43. Roseman RR, Pirrotta V, Geyer PK. The su(Hw) protein insulates expression of the Drosophila melanogaster white gene from chromosomal position-effects. EMBO J. 1993;12(2):435-442.

44. Moon AM, Ley TJ. Conservation of the primary structure, organization, and function of the human and mouse beta-globin locus-activating regions. Proc Natl Acad Sci US A. 1990;87(19):7693-7697.

45. Nishimura S, et al. A GATA box in the GATA-1 gene hematopoietic enhancer is a critical element in the network of GATA factors and sites that regulate this gene. Mol Cell Biol. 2000;20(2):713-723.

46. Frazar TF, et al. Variegated expression from the murine band 3 (AE1) promoter in transgenic mice is associated with mRNA transcript initiation at upstream start sites and can be suppressed by the addition of the chicken beta-globin 5' HS4 insulator element. Mol Cell Biol. 2003;23(14):4753-4763.

47. Avramova Z, Tikhonov A. Are scs and scs' 'neutral' chromatin domain boundaries of the locus? Trends Genet. 1999;15(4):138-139.

48. Bi X, Broach JR. UASrpg can function as a heterochromatin boundary element in yeast. Genes Dev. 1999;13(9):1089-1101.

49. Udvardy A, Maine E, Schedl P. The 87A7 chromomere. Identification of novel chromatin structures flanking the heat shock locus that may define the boundaries of higher order domains. J Mol Biol. 1985;185(2):341-358.

50. Mutskov VJ, Farrell CM, Wade PA, Wolffe AP, Felsenfeld $G$. The barrier function of an insulator couples high histone acetylation levels with specific protection of promoter DNA from methylation. Genes Dev. 2002;16(12):1540-1554.

51. Huang S, Litt M, Felsenfeld G. Methylation of histone $\mathrm{H} 4$ by arginine methyltransferase PRMT 1 is essential in vivo for many subsequent histone modifications. Genes Dev. 2005;19(16):1885-1893.

52. Huang S, Li X, Yusufzai TM, Qiu Y, Felsenfeld G. USF1 recruits histone modification complexes and is critical for maintenance of a chromatin barrier. Mol Cell Biol. 2007;27(22):7991-8002.

53. Nilson DG, Sabatino DE, Bodine DM, Gallagher PG. Major erythrocyte membrane protein genes in EKLFdeficient mice. Exp Hematol. 2006;34(6):705-712.

54. Armstrong JA, Bieker JJ, Emerson BM. A SWI/SNFrelated chromatin remodeling complex, E-RC1, is required for tissue-specific transcriptional regulation by EKLF in vitro. Cell. 1998;95(1):93-104.

55. Gallagher PG, et al. A dinucleotide deletion in the ankyrin promoter alters gene expression, transcription initiation and TFIID complex formation in hereditary spherocytosis. Hum Mol Genet. 2005;14(17):2501-2509.

56. Attal J, et al. The effect of matrix attached regions (MAR) and specialized chromatin structure (SCS) on the expression of gene constructs in cultured cells and in transgenic mice. Mol Biol Rep.
1995;22(1):37-46.

57. Recillas-Targa F, Valadez-Graham V, Farrell CM. Prospects and implications of using chromatin insulators in gene therapy and transgenesis. Bioessays. 2004;26(7):796-807.

58. Potts W, Tucker D, Wood H, Martin C. Chicken beta-globin 5'HS4 insulators function to reduce variability in transgenic founder mice. Biochem Biophys Res Commun. 2000;273(3):1015-1018.

59. Aker M, et al. Extended core sequences from the cHS4 insulator are necessary for protecting retroviral vectors from silencing position effects. Hum Gene Ther. 2007;18(4):333-343.

60. Taboit-Dameron F, et al. Association of the 5'HS4 sequence of the chicken beta-globin locus control region with human EF1 alpha gene promoter induces ubiquitous and high expression of human CD55 and CD59 cDNAs in transgenic rabbits. Transgenic Res. 1999;8(3):223-235.

61. Burgess-Beusse B, et al. The insulation of genes from external enhancers and silencing chromatin. Proc Natl Acad Sci U S A. 2002;99(suppl 4):16433-16437.

62. Steiner LA, Lin JY, Owens AN, Sangerman JI, Bodine DM, Gallagher PG. Alternate promoters direct tissue-specific expression of erythrocyte ankyrin transcripts with novel NH2-termini. ASH Annual Meeting Abstracts. 2007;110(11):1710.

63. Gallagher PG, Wong E, Wong C. A novel isoform of ankyrin 1 (ANK1) expressed in brain, heart and skeletal muscle is directed by an alternate promoter. Blood. 1998;92:300a.

64. Gallagher PG, Forget BG. An alternate promoter directs expression of a truncated, muscle- specific isoform of the human ankyrin 1 gene. J Biol Chem. 1998;273(3):1339-1348.

65. Birkenmeier CS, White RA, Peters LL, Hall EJ, Lux SE, Barker JE. Complex patterns of sequence variation and multiple 5' and 3 ' ends are found among transcripts of the erythroid ankyrin gene. J Biol Chem. 1993;268(13):9533-9540.

66. Birkenmeier CS, Sharp JJ, Gifford EJ, Deveau SA, Barker JE. An alternative first exon in the distal end of the erythroid ankyrin gene leads to production of a small isoform containing an $\mathrm{NH} 2$-terminal membrane anchor. Genomics. 1998;50(1):79-88.

67. Lunyak VV, et al. Developmentally regulated activation of a SINE B2 repeat as a domain boundary in organogenesis. Science. 2007;317(5835):248-251.

68. Noma K, Cam HP, Maraia RJ, Grewal SI. A role for TFIIIC transcription factor complex in genome organization. Cell. 2006;125(5):859-872.

69. Scott KC, Merrett SL, Willard HF. A heterochromatin barrier partitions the fission yeast centromere into discrete chromatin domains. Curr Biol. 2006;16(2):119-129.

70. Valenzuela L, Dhillon N, Kamakaka RT. Transcription independent insulation at TFIIIC-dependent insulators. Genetics. 2009;183(1):131-148.

71. Simms TA, et al. TFIIIC binding sites function as both heterochromatin barriers and chromatin insulators in Saccharomyces cerevisiae. Eukaryot Cell. 2008;7(12):2078-2086.

72. Singh G, Klar AJ. Mutations in deoxyribonucleotide biosynthesis pathway cause spreading of silencing across heterochromatic barriers at the mating-type region of the fission yeast. Yeast. 2008;25(2):117-128.

73. Noma K, Allis CD, Grewal SI. Transitions in distinct histone $\mathrm{H} 3$ methylation patterns at the heterochromatin domain boundaries. Science. 2001; 293(5532):1150-1155.

74. Sharp AJ, Spotswood HT, Robinson DO, Turner BM, Jacobs PA. Molecular and cytogenetic analysis of the spreading of $\mathrm{X}$ inactivation in $\mathrm{X}$; autosome translocations. Hum Mol Genet. 2002;11(25):3145-3156.

75. Kleinjan DA, van Heyningen M. Long-range control of gene expression: emerging mechanisms and disruption in disease. AmJ Hum Genet. 2005;76(1):8-32. 76. Filippova GN, et al. CTCF-binding sites flank
CTG/CAG repeats and form a methylation-sensitive insulator at the DM1 locus. Nat Genet. 2001; 28(4):335-343.

77. Prawitt D, et al. Microdeletion of target sites for insulator protein CTCF in a chromosome $11 \mathrm{p} 15$ imprinting center in Beckwith-Wiedemann syndrome and Wilms' tumor. Proc Natl Acad Sci U S A. 2005;102(11):4085-4090.

78. Epstein DJ. Cis-regulatory mutations in human disease. Brief Funct Genomic Proteomic. 2009; $8(4): 310-316$.

79. Wray GA. The evolutionary significance of cis-regulatory mutations. Nat Rev Genet. 2007;8(3):206-216.

80. Park PJ. ChIP-seq: advantages and challenges of a maturing technology. Nat Rev Genet. 2009; 10(10):669-680.

81. Farnham PJ. Insights from genomic profiling of transcription factors. Nat Rev Genet. 2009; 10(9):605-616.

82. Barski A, Zhao K. Genomic location analysis by ChIP-Seq. J Cell Biochem. 2009;107(1):11-18.

83. Kadauke S, Blobel GA. Chromatin loops in gene regulation. Biochim Biophys Acta. 2009;1789(1):17-25.

84. Ko M, Sohn DH, Chung H, Seong RH. Chromatin remodeling, development and disease. Mutat Res. 2008;647(1-2):59-67.

85. Panzenbock B, Bartunek P, Mapara MY, Zenke M. Growth and differentiation of human stem cell factor/erythropoietin-dependent erythroid progenitor cells in vitro. Blood. 1998;92(10):3658-3668.

86. Migliaccio AR, Migliaccio G, Di Baldassarre A, Eddleman K. Circulating hematopoietic progenitor cells in a fetus with alpha thalassemia: comparison with the cells circulating in normal and non-thalassemic anemia fetuses and implications for in utero transplantations. Bone Marrow Transplant. 2002;30(2):75-80.

87. Zhang J, Socolovsky M, Gross AW, Lodish HF. Role of Ras signaling in erythroid differentiation of mouse fetal liver cells: functional analysis by a flow cytometry-based novel culture system. Blood. 2003;102(12):3938-3946.

88. Lowrey CH, Bodine DM, Nienhuis AW. Mechanism of DNase I hypersensitive site formation within the human globin locus control region. Proc Natl Acad SciU S A. 1992;89(3):1143-1147.

89. Nemeth MJ, Bodine DM, Garrett LJ, Lowrey CH. An erythroid-specific chromatin opening element reorganizes beta-globin promoter chromatin structure and augments gene expression. Blood Cells Mol Dis. 2001;27(4):767-780.

90. Recillas-Targa F, Bell AC, Felsenfeld G. Positional enhancer-blocking activity of the chicken beta-globin insulator in transiently transfected cells. Proc Natl Acad Sci U S A. 1999;96(25):14354-14359.

91. Hogan B, Costantini F, Lacy E. Manipulating the Mouse Embryo: A Laboratory Manual, Cold Spring Harbor Laboratory. Cold Spring Harbor, New York, USA: Cold Spring Harbor Laboratory Press; 1986.

92. Thorpe SJ, Thein SL, Sampietro M, Craig JE, Mahon B, Huehns ER. Immunochemical estimation of haemoglobin types in red blood cells by FACS analysis. Br J Haematol. 1994;87(1):125-132.

93. Vieira KF, et al. Recruitment of transcription complexes to the beta-globin gene locus in vivo and in vitro. J Biol Chem. 2004;279(48):50350-50357.

94. Espada J, et al. Human DNA methyltransferase 1 is required for maintenance of the histone $\mathrm{H} 3$ modification pattern. J Biol Chem. 2004;279(35):37175-37184.

95. Kleinschmidt MA, Streubel G, Samans B, Krause M, Bauer UM. The protein arginine methyltransferases CARM1 and PRMT1 cooperate in gene regulation. Nucleic Acids Res. 2008;36(10):3202-3213.

96. Zhou X, et al. MHC class II transactivator represses human IL-4 gene transcription by interruption of promoter binding with CBP/p300, STAT6 and NFAT1 via histone hypoacetylation. Immunology. 2007;122(4):476-485. 